Gut and Liver, Vol. 9, No. 5, September 2015, pp. 571-589

REVIEW

\title{
Prevalence, Diagnosis and Management of Pancreatic Cystic Neoplasms: Current Status and Future Directions
}

\author{
James J. Farrell \\ Yale Center for Pancreatic Diseases, Interventional Endoscopy, Yale School of Medicine, New Haven, CT, USA
}

Cystic neoplasms of the pancreas are found with increasing prevalence, especially in elderly asymptomatic individuals. Although the overall risk of malignancy is very low, the presence of these pancreatic cysts is associated with a large degree of anxiety and further medical investigation due to concerns about malignancy. This review discusses the different cystic neoplasms of the pancreas and reports diagnostic strategies based on clinical features and imaging data. Surgical and nonsurgical management of the most common cystic neoplasms, based on the recently revised Sendai guidelines, is also discussed, with special reference to intraductal papillary mucinous neoplasm (IPMN; particularly the branch duct variant), which is the lesion most frequently identified incidentally. IPMN pathology, its risk for development into pancreatic ductal adenocarcinoma, the pros and cons of current guidelines for management, and the potential role of endoscopic ultrasound in determining cancer risk are discussed. Finally, surgical treatment, strategies for surveillance of pancreatic cysts, and possible future directions are discussed. (Gut Liver 2015;9:571-589)

Key Words: Intraductal papillary mucinous neoplasm; Pancreatic cyst; Endoscopic ultrasound; Cyst fluid

\section{PREVALENCE}

Cystic neoplasms of the pancreas (CNP) were once considered extremely rare (many textbooks perpetuated the notion that most cystic lesions of the pancreas were pseudocysts, and $<10 \%$ were neoplasms), and in fact were often the subject of case reports (Table 1). The distinction between serous and mucinous pancreatic cystic neoplasms was made about 40 years ago and the nomenclature defining intraductal papillary mucinous neoplasms (IPMNs) is only 20 years old. The increasing numbers
Table 1. Classification of Cystic Neoplasms of the Pancreas (Including Lesions That Resemble Them)

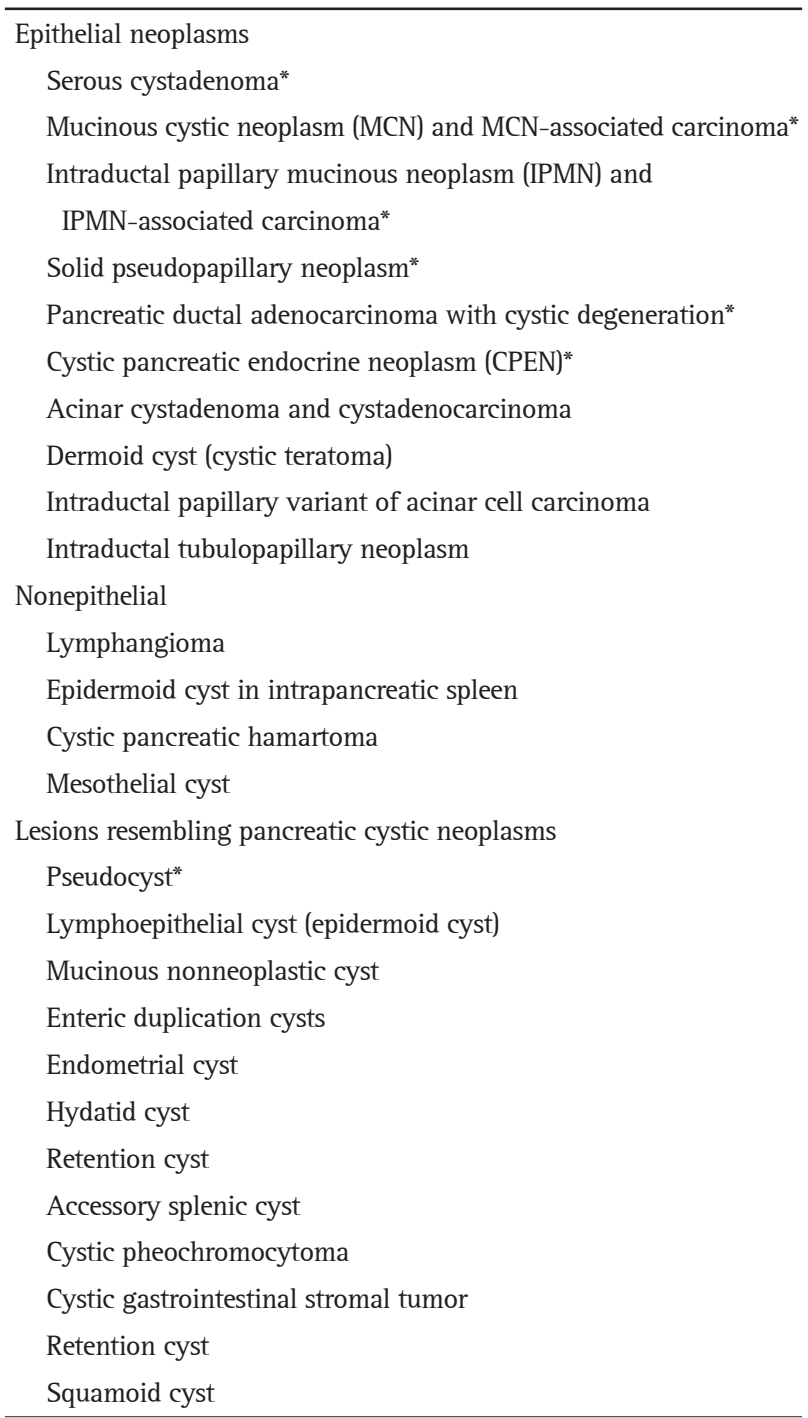

*Clinically common and important diseases.

Correspondence to: James J. Farrell

Section of Digestive Diseases, Yale University School of Medicine, LMP 1080, 15 York Street, New Haven, CT 06510-3221, USA

Tel: +1-203-785-6228, Fax: +1-203-737-1755, E-mail: james.j.farrell@yale.edu

Received on February 6, 2015. Accepted on April 28, 2015.

pISSN 1976-2283 eISSN 2005-1212 http://dx.doi.org/10.5009/gnl15063

@) This is an Open Access article distributed under the terms of the Creative Commons Attribution Non-Commercial License (http://creativecommons.org/licenses/by-nc/4.0) which permits unrestricted non-commercial use, distribution, and reproduction in any medium, provided the original work is properly cited. 
of cases that we are now seeing is in part related to increased awareness of their existence, but without doubt is mostly due to increased use of cross-sectional imaging, which has led to incidental discovery of many pancreatic cysts. Studies using computed tomography (CT) and magnetic resonance imaging (MRI) have shown that the prevalence of pancreatic cysts (in individuals without history of symptoms of pancreatic disease) is about $2.5 \%{ }^{1,2}$ and that this increases with age to the point that $10 \%$ of persons 70 years or older have a pancreatic cyst. ${ }^{1}$ For studies using only MRI imaging looking for the prevalence pancreatic cysts, the reported prevalence rates of pancreatic cysts varies from $2 \%$ to $38 \%$ with an overall prevalence rate of $15 \%$, compared with studies which used just CT scans, which reported a prevalence rate of $3 \%$ for pancreatic cysts. ${ }^{1-7}$ Where reported, the prevalence rate for pancreatic cysts greater than 2 $\mathrm{cm}$ in these imaging studies was $0.8 \% \%^{1,5-7}$ However when looking at prevalence based on age group there was a difference in prevalence across differing age groups: $0.5 \%$ in those less than 40 years of age, 25\% in those 70-79 years of age, and 37\% in those aged 80 or over. This corresponds with a prior autopsy study which found pancreatic cysts in 19\% of those between the age of 70 to 79 years and 30\% in those 80 to 89 years of age. ${ }^{8}$

Most of these asymptomatic incidental pancreatic cysts are likely to be small branch duct IPMNs, but firm pathologic proof is lacking. However this is balanced by suggestion from analysis of a SEER database that the overall malignant transformation of these cysts is very rare, with 1,137 mucin-producing pancreatic adenocarcinomas being reported in a population of approximately 3.5 million pancreatic cysts. ${ }^{9}$ Nonetheless, because of the known malignant potential of this diagnosis, their identification generates anxiety, need for subsequent imaging, and sometimes invasive testing or surgery. This high prevalence of cysts then translates into high resource utilization including repeat imaging, invasive procedures such as endoscopic ultrasound (EUS) +/- fine-needle aspiration (FNA) and surgical resections, especially in patients of an advanced age who have a high prevalence of pancreatic cysts.

\section{DIAGNOSIS AND MANAGEMENT}

There are two major aspects to the effective diagnosis and management of pancreatic cystic neoplasms. The first is the differentiation between pancreatic cystic neoplasms and pancreatic pseudocysts. Originally, inflammatory pseudocysts were felt to account for the majority of pancreatic cysts. However with the increased use of high resolution abdominal imaging, especially in asymptomatic individuals, especially those without a history of pancreatitis, it is becoming obvious that these neoplastic pancreatic cysts are far more common than pancreatic pseudocysts. Where antecedent imaging is available prior to an attack of pancreatitis, a diagnosis of a pancreatitis fluid collection can be confidently made. When a cyst is seen in the pancreas without evidence of an associated mass, but with extensive chronic pancreatitis, then the clinical diagnosis favors a pancreatic pseudocyst. However the ability to confidently diagnose a pancreatic pseudocyst is reduced if the pancreatic cyst arises without a prior episode of pancreatitis and if there is minimal evidence to support acute or chronic pancreatitis on imaging. To further complicate the diagnostic workup, pancreatic cystic neoplasms, particularly IPMNs can result in acute pancreatitis.

The other major component of the effective diagnosis of pancreatic cystic neoplasms is the understanding of the underlying pathologies of pancreatic cystic neoplasms, their varying degrees of malignant risk, and the role of imaging and cyst fluid analysis in sorting these issues out. This will be the focus of the remainder of this review.

\section{MUCINOUS CYSTIC NEOPLASM}

The mucinous cystic neoplasm of the pancreas (MCN) is a relatively uncommon tumor that comprises about a quarter of all resected cystic neoplasms of the pancreas in large surgical series. ${ }^{10}$ This tumor is predominantly seen women (>95\%) and in the distal pancreas (>95\%), and, unlike branch duct IPMNs, is always a single lesion. ${ }^{11-13}$

Macroscopically, MCNs present as a round large mass (ranging up to $35 \mathrm{~cm}$ ) with a fibrous pseudocapsule of variable thickness and frequent calcifications. Although typically unilocular, they can be multilocular, which in addition to the presence of internal papillary projections and/or mural nodules, correlates significantly with malignancy. ${ }^{14,15}$ The presence of a dense ovarian-like stroma surrounding the tumor and an inner epithelial layer with tall, mucin-producing cells are pathognomonic histologic findings. This ovarian-like stroma shows positivity for vimentin, smooth muscle actin, progesterone receptors and estrogen receptors. The epithelium can display areas with pseudopyloric, gastric foveolar, small and colonic intestinal differentiation, with scattered neuroendocrine cells, in addition to the various degrees of atypia, ranging from noninvasive to invasive carcinoma. Based on the highest degree of architectural and cytologic atypia, noninvasive MCNs are subcategorized into MCN with low-grade dysplasia, moderate dysplasia, or highgrade dysplasia (carcinoma-in-situ). Up to one-third of MCN in surgical resection series are associated with an invasive cancer, which resembles the typical pancreatic ductal adenocarcinoma, with the presence of colloid carcinoma being very rare. ${ }^{16}$ The epithelial markers include EMA, carcinoembryonic antigen (CEA), cytokeratins (7, 8, 18, and 19) and the gastric foveolar type markers MUC5AC, with MUC1 seen in high grade MCNs and invasive carcinoma. SMAD4 protein is typically intact in noninvasive MCNs but may be lost in the invasive carcinoma component. $^{14}$

Similar to studies of preinvasive pancreatic ductal adenocarcinoma, K-ras mutations in codon 12 have been described in 
early low-grade dysplastic MCNs, increasing in frequency with advancing degrees of dysplasia and invasive cancer. ${ }^{17}$ Mutations in p53 and SMAD4 typically occur in high-grade dysplasia and invasive carcinomas. ${ }^{18,19}$ RNF43, a suppressor gene that codes for a protein with intrinsic E3 ubiquitin ligase activity, is also mutated in both MCNs and IPMNs. However, it appears that GNAS mutations are found uniquely in many (although not all) IPMNs and are not seen in MCNs. ${ }^{19}$

The predominance in women, the predilection for the pancreatic tail, and the shared clinical and pathologic features with mucinous cystic neoplasms in the liver and retroperitoneum, suggests a unique pathogenesis. For examples, the left primordial gonad and the dorsal pancreatic anlage (which gives rise to the pancreatic body and tail) and a portion of the head of the pancreas, lie in close proximity at an early (fourth to fifth week) stage of development. ${ }^{14,20}$ It has been proposed that ectopic ovarian stroma in the pancreas tail, biliary tree and retroperitoneum, may release hormones and growth factors, stimulating local endodermally-derived epithelium to proliferate and form cystic tumors.

Clinically, the median age of diagnosis is 45 and 48 years (range, 16 to 84 years), and most patients present either incidentally or with vague symptoms, although about $10 \%$ have presented with acute pancreatitis and $12 \%$ with a palpable mass. ${ }^{11,12}$ The typical radiologic presentation is that of a thickwalled single cyst located in the neck, body, or tail of the pancreas, often with septations, and occasionally with nodules or calcifications. ${ }^{13}$ Both MCN and IPMN typically have elevated cyst levels of CEA, which can be used to differentiate from macrocystic serous cystadenoma, but MCN can be difficult to preoperatively differentiate from IPMN. ${ }^{21,22}$ While the absence of communication between the main pancreatic duct and the cyst may favor the diagnosis of MCN over IPMN, communication between the main pancreatic duct and the cyst on endoscopic retrograde cholangiopancreatography (ERCP) has been seen in up to $15 \%$ of pathologically confirmed cases of cases. ${ }^{12}$ Similarly, underfilling of the branch ducts with contrast at ERCP, due to mucin plugs may also been seen in cases of IPMN. However, both MCN and IPMN typically have elevated cyst levels of CEA, which can be used to differentiate from macrocystic serous cystadenoma. $^{21,22}$

The risk of malignancy in MCN is $17.5 \%$. In one surgical series, all malignant tumors had either nodules, or had a size $>4 \mathrm{~cm} .{ }^{11}$ Because malignant MCNs are significantly larger (8.2 cm vs $4.5 \mathrm{~cm}$ ) and are diagnosed in older patients (49.5 years vs 44 years), it is presumed that the tumor evolves slowly over time; however, the relatively low frequency of cancer suggests that not all MCNs progress, and identifying those patients who are not at risk and could potentially be spared an operation is a desirable goal. Currently, treatment is surgical resection. The basis for this universal recommendation of surgery is based on the fact that the majority of the patients are young and would otherwise require lengthy surveillance; most of the lesions are located in the body and tail of the pancreas where surgical management in high volume experienced centers carries negligible mortality and low morbidity; and unlike IPMN, MCN do not require surveillance after surgical resection (unless there is evidence of invasive cancer). ${ }^{23}$ Patients with small presumed MCNs (unilocular, pancreatic body/tail location, female gender, middle age, elevated cyst fluid CEA) that are devoid of nodules, and elderly patients, can potentially be managed with observation, but life-long close surveillance is mandatory.

The prognosis is excellent unless there is invasive carcinoma with either extracapsular or diffuse intracapsular infiltration. ${ }^{11}$ The overall 5-year survival of invasive mucinous cystadenocarcinoma is $62 \%$, being worse in patients over the age of 50 years of age, and those with tumor wall and peritumoral invasion. ${ }^{12}$

\section{SEROUS CYSTADENOMA}

Serous cystadenoma of the pancreas (SCA) is a benign, slowgrowing tumor that affects predominantly women ( 75\%); the mean age of resected patients has been 62 years. ${ }^{24-27}$ SCA account for about $16 \%$ of resected cystic tumors of the pancreas. Morphologically, the typical SCA is a tumor formed by many tiny cysts lined by a cuboidal epithelium that is glycogen rich, and has a "honeycomb" appearance, but a variant that is oligocystic or macrocystic has also been described in about 10\% of cases. ${ }^{25,28}$ Very few cases of malignant serous cystadenoma (on the basis of presence of concomitant tumors in the liver or other extrapancreatic sites) have been described, and represent $<1 \%$ of cases. ${ }^{24,29,30}$ In one pathology series, head location and large size were predictive of aggressive behavior, defined as direct invasion into adjacent organs or blood vessels, or metastasis to lymph nodes or other organs. ${ }^{31}$ SCA can be located anywhere in the pancreas. Most are currently diagnosed incidentally, but depending on their location and size, they can occasionally cause jaundice, pancreatitis, abdominal pain, or present as a palpable mass. Because this is a benign tumor, treatment, which is surgical resection, should be driven by the presence of symptoms, rather than the very low risk of malignancy. Patients managed nonoperatively may be monitored with imaging at periodic intervals to ensure that rapid growth (making likelihood of symptoms higher and also potentially leading to a bigger or more complex operation) is not occurring. ${ }^{25,32-34}$

Management by observation with or without serial imaging is dependent on having a secure diagnosis. This is sometimes derived from a classical radiologic appearance, which is that of a "spongy" multilobular mass, often with a central calcification. However central calcification is only seen in about 30\% of cases. The radiologic finding can on occasion be confused with a solid pancreatic endocrine neoplasm. ${ }^{35-37}$ For this reason, EUS-guided biopsy and aspiration of fluid may be needed to support the diagnosis. ${ }^{38}$ Fluid from SCAs characteristically have 
very low CEA levels (typically $<5 \mathrm{ng} / \mathrm{mL}$ ), but can often be difficult to acquire from the microcystic variant compared with the oligocystic variant. The oligocystic variant is much harder to diagnose as its radiologic features overlap with MCN and branch duct IPMN. In this clinical situation, the presence of small peripheral cysts on imaging such as EUS, and the low CEA level, support the diagnosis of a oligocystic serous cystadenoma. ${ }^{21}$

Patients with von Hippel-Lindau (VHL) syndrome may be found to have multiple oligocystic SCA in up to $12 \%$ of cases. $^{39}$ These VHL-related SCA follow a benign course, with resection again being reserved primarily for symptomatic patients. ${ }^{40}$ Sporadic SCA have genetic alterations, including VHL mutations and overexpression of vascular endothelial growth factor (VEGF), that are also seen in the VHL syndrome. ${ }^{41}$ Up to $40 \%$ of sporadic SCA have allelic loss in chromosome 3, the site of the VHL gene. ${ }^{42}$ As in other VHL-related clear cell tumors, there is a prominent capillary network immediately adjacent to the epithelium of SCA, confirming that the clear cell-angiogenesis association is also valid for this tumor type. Molecules implicated in clear cell tumorigenesis (e.g., CD31, VEGF, HIF-1 $\alpha$ ) are also consistently expressed in SCA. This may have biologic and therapeutic implications, especially considering the rapidly evolving drugs against these pathways. ${ }^{43}$

\section{SOLID PSEUDOPAPILLARY NEOPLASM}

The solid pseudopapillary neoplasm of the pancreas (SPN) is a very uncommon lesion that comprises less than $4 \%$ of resected pancreatic cystic tumors. Prior to its inclusion in the World Health Organization classification, it had previously been known by a variety of different names including papillary epithelial neoplasm of the pancreas, solid and cystic tumor of the pancreas, adenocarcinoma of the pancreas of childhood, papillary-cystic tumor and solid and papillary epithelial neoplasm. ${ }^{44}$ It predominantly affects women ( $>80 \%$ ), and the median age has been between 30 and 38 years, with about 20\% to 25\% of cases being seen in the pediatric population. ${ }^{45-47}$

SPNs can be located anywhere in the pancreas, and can be an incidental finding or present with a variety of symptoms, including abdominal pain, pancreatitis, jaundice, or a palpable mass. Due to its slow growth, SPN often remain asymptomatic, until the tumor has enlarged considerably. Radiologically, it presents as a well-demarcated heterogeneous mass with solid and cystic components, with a peripheral capsule which rarely shows calcification, and EUS-guided FNA or core biopsy is often diagnostic, showing uniform cells forming microadenoid structures, branching, papillary clusters with delicate fibrovascular cores. Immunohistochemical analysis can be used to confirm the diagnosis. ${ }^{48}$ Some cases show reactivity with S-100 and weak reactivity with epithelial markers such as AE1/AE3 and CAM 5.2 (CK8). Progesterone receptor positivity and abnormal nuclear and cytoplasmic $\beta$-catenin expression are also com- monly seen. Neuroendocrine markers such as synaptophysin show focal reactivity, and as a result the additional presence of galectin-3 and CD10 are used to differentiate SPN from endocrine neoplasms. Overall, the proliferation (Ki-67) index is low $(<5 \%)$, further confirming the slow growth of the tumor. SPN is genetically distinct from ductal adenocarcinoma, and is characterized by activation of the $\beta$-catenin pathway, with $\beta$-catenin mutations, alterations of the Wnt pathway and disorganization of E-cadherin detected in up to $90 \%$ of SPN. ${ }^{49-52}$ Cyclin D1, a downstream transcriptional target of $\beta$-catenin, is overexpressed in most cases. ${ }^{53}$ The common expression of progesterone and the strong predilection for females suggests a hormone dependent tumor (but estrogen receptors are not typically found). ${ }^{54}$

Most SPNs exhibit a benign behavior, and even the less than $20 \%$ that have vascular or perineural invasion, lymph node involvement or liver metastases can have a very indolent course. $^{45-47}$ Rarely, presentations including multicentric tumors in the pancreas and extrapancreatic sites, such as mesocolon, retroperitoneum, omentum, liver and duodenum, possible due to synchronous spread, have been seen. Although the Ki-67 proliferation index has been suggested as a potential malignant indicator, clear-cut criteria for malignancy have not been established, and it is not possible to predict behavior and natural history of SPN based on histologic grounds including size. ${ }^{48}$ Hence, treatment is surgical resection. Tumor enucleation and incomplete tumor resection are to be avoided due to the high risk of tumor dissemination and higher recurrence rate. Chemotherapy or radiotherapy in the adjuvant, neoadjuvant or metastatic setting have no defined role in the management of this disease. ${ }^{55}$ The overall 5-year survival is close to 97\% in patients undergoing surgical resection. Death caused directly by the tumor is rare, and long-term survival has been described even in the presence of asymptomatic disseminated disease.

\section{CYSTIC PANCREATIC ENDOCRINE NEOPLASM}

Cystic pancreatic endocrine neoplasms (CPEN) represent about $8 \%$ of resected cystic tumors of the pancreas, ${ }^{10}$ and between $10 \%$ and $17 \%$ of resected pancreatic neuroendocrine tumors. ${ }^{56-58}$ Most of them are incidentally discovered and nonfunctional, but rarely can be functional. CPENs are more likely to occur in patients with multiple endocrine neoplasia type I (MEN I), and have also been reported in von Hippel-Lindau and Wermer syndromes. ${ }^{58,59}$ While typically unifocal, they have been reported to be rarely multifocal. ${ }^{60}$ There is no gender predilection, and the mean age of diagnosis is in the sixth decade. ${ }^{60-63}$ Radiologically, they present as a cystic lesion, not infrequently with a hypervascular rim and occasionally with septation or a solid component within it. ${ }^{56}$ Microcystic degeneration of large solid pancreatic endocrine neoplasms may occur, but they may also arise in a thin-walled cysts, which may be morphologically indistinguishable from MCNs and contain variable degrees 
of focal or concentric wall thickening. ${ }^{64}$ Large proportions are indistinguishable from other pancreatic cystic neoplasms on preoperative CT or MRI imaging. ${ }^{60}$ Fluid aspirated by EUS characteristically has very low CEA levels and the yield of FNA cytology is high, compared with other CNPs (73\% vs 20\%). ${ }^{61,65}$ In comparison with their solid counterparts, CPENs are less likely to demonstrate tumor necrosis, perineural invasion, vascular invasion, regional lymph node metastasis, and synchronous distant metastasis. ${ }^{60}$ Several series have demonstrated pancreatic cystic endocrine neoplasms with malignant potential. ${ }^{66-68}$ Like all endocrine pancreatic tumors, malignancy is difficult to predict based on biopsy alone (either cytology or core biopsy), or even with examination of the resected tumor at the time of surgical resection. Currently, surgical resection is recommended for all patients, and long-term survival is excellent (>85\%). ${ }^{56-58}$

Both solid and cystic pancreatic endocrine tumors are being incidentally-discovered with increasing frequency. While conventional wisdom has been to resect all of these lesions (given their uncertain behavior), this has been challenged. A recent paper described observation alone in a cohort of 77 patients with small, nonfunctioning PENs with results that were no different than surgical management. ${ }^{69}$ Whether this extends as well to CPEN is unclear.

\section{INTRADUCTAL PAPILLARY MUCINOUS NEOPLASM}

The term "mucinous ductal ectasia" was used for many years to describe an entity characterized by gross dilation of the pancreatic duct due to overproduction of mucus from a proliferative epithelium with papillary growth. The tumor occasionally eroded into the duodenum or bile duct, and patients often had exhibited pancreatitis-like symptoms for years. While cancer was often present in the tumor, not infrequently it was confined to the duct or was minimally invasive. This disease is now recognized to be an advanced form of main-duct intraductal papillary mucinous neoplasm (MD-IPMN), and we now recognize that this neoplastic proliferation can involve the side branches of the pancreatic ductal system, either alone (branch-duct IPMN or BD-IPMN), or in combination (mixed or combined IPMN). ${ }^{70}$ The risk of malignant transformation in mixed IPMNs is similar to that of MD-IPMN, and they are managed in a similar manner to MD-IPMN. Although carcinomatous invasion is reported in $30 \%$ to $50 \%$ of MD-IPMN or mixed-IPMN, the sensitivity of preoperative imaging is imperfect, with less than $80 \%$ of invasive cancers detected preoperatively. ${ }^{71-74}$ The branch duct variant (BD-IPMN) for a long time was confused with mucinous cystic neoplasms, which has a different epidemiology and risk of cancer when compared to main and combined type IPMN (both of which share most features), based primarily on differing histologic subtypes which can only be determined by surgical pathology. ${ }^{75,76}$ The overall risk of carcinomatous transformation in BD-IPMN is $24 \%$ in surgically resected series, and is estimated to be between $1 \%$ and $2 \%$ per year in surveillance studies. ${ }^{23,77}$

IPMN are increasingly detected, with a dramatic increase in the number of patients with IPMN undergoing surgical resection, accounting for up to 50\% of all resected pancreatic cysts (compared with 3\% before 1990). ${ }^{10,78}$ With the increased use of cross-sectional imaging for the work-up of pancreatic and nonpancreatic conditions, the most common presentation of IPMNs has changed over the years, with most IPMNs, especially BDIPMNs, found incidentally. Overall, symptoms are present in $2 \%$ to $20 \%$ of patients, especially abdominal pain, pancreatitis and jaundice. $^{10,79,80}$ The 5-year survival rate for surgically resected noninvasive IPMNs is $90 \%$ to $100 \%$, while that for surgically resected invasive IPMNs is $31 \%$ to $60 \%$. Colloid type carcinoma has a better prognosis than tubular type. However, overall IPMN-associated cancers have a better prognosis than regular pancreatic ductal adenocarcinoma (PDAC) when matched for pathologic features, until lymph nodes become involved, at which stage both IPMN associated cancer and PDAC share a similar bad prognosis. ${ }^{81}$

Microscopically, the epithelial component of the IPMN, either the lining of the main ecstatic duct or the cystically dilated branch ducts, is divided into noninvasive or invasive neoplasms. The noninvasive IPMNs are graded on the basis of the greatest degree of dysplasia, and classified into low-grade, moderategrade and high-grade dysplasia or carcinoma-in-situ. Invasive IPMNs are either colloid or tubular, with the latter (the tubular carcinoma) having a worse prognosis, similar to conventional PDAC. $^{82-84}$ Further histologic subtyping of epithelial differentiation is based on the cell lineage, the morphology of the papillae and the immunophenotype, and include classification into intestinal, gastric, pancreaticobiliary and oncocytic subtypes. $^{71,82,84-86}$ Differentiating these epithelia subtypes is clinically relevant because of the specific risk of malignant transformation associated with each subtype. Early IPMNs show pure lineage features as well as a single grade of differentiation, whereas the more advanced neoplasms exhibit a mixture of cell lineage, heterogeneous grade of differentiation, and co-express different immunohistochemical markers. For example, the gastric subtype of epithelium can be seen in association with the pancreaticobiliary type of IPMNs, whereas is it uncommon to find intestinal and pancreaticobiliary epithelium within the same IPMN.

The epithelial lining of most MD-IPMNs has an intestinal phenotype, and expresses the typical intestinal lineage markers CDX2 and MUC2, and co-express the foveolar marker MUC5AC. They do not express MUC1 and MUC6. ${ }^{70}$ MD-IPMNs exhibit a wide heterogeneity of dysplasia within the tumor (similar to villous adenomas of the colon). The risk of harboring malignancy is high, with invasive carcinoma found in 45\% of cases, and high-grade dysplasia (i.e., carcinoma-in-situ) in an additional $20 \% .^{75}$ The invasive carcinomas arising from intestinal type IPMN are often of the colloid variety, which has a more indolent behavior. ${ }^{52,82,84}$ 
The majority of BD-IPMNs have a gastric type epithelium: MUC5AC-positive but MUC1-negative, with MUC2 highlighting only the scattered goblet cells; although other histologic BDIPMN subtypes (oncocytic, intestinal and pancreaticobiliary) exist. ${ }^{84,86,87}$ Gastric type BD-IPMNs are typically low-grade, with a small percentage developing usually a tubular type adenocarcinoma, which has the same histologic features and bad prognosis as conventional PDAC. It has been hypothesized that pancreatic duct glands give rise to both PanIN (pancreatic intraepithelial neoplasm, the precursor of PDAC) and gastric type BD-IPMN, suggesting a similar biology and outcome..$^{52,84,88}$ This concept is also supported by the increased prevalence of pancreatic cysts (presumed BD-IPMN) in high risk pancreatic cancer families. ${ }^{89}$ In fact, the differentiation of gastric IPMNs from PanIN-1 is only based on the size and cystic dilatation. Both gastric IPMNs and PanIN lesions can be associated with foci of lobular fibrosis, and immunostain for MUC5AC. These observations raise the question of whether gastric-type IPMNs are features of diffuse PanIN-1 disease rather than individual disorders. ${ }^{90}$

Pancreaticobiliary-type IPMNs are less common, typically involve the main pancreatic duct, have cells that are MUC1 and MUC5AC positive, and MUC2, MUC6 and CDX2 negative, and are usually associated with high-grade dysplasia. Invasive carcinomas associated with this subtype have features of the common pancreatic ductal adenocarcinoma. ${ }^{86,91}$ Oncocytic-type IPMNs arise most frequently in MD-IPMN and can extend into the branch ducts. They are characterized by the presence of oncocytic cells (an epithelial cell characterized by an excessive amount of mitochondria, resulting in an abundant acidophilic, granular cytoplasm) and typically show severe atypical or carcinoma-in-situ, being diffusely positive for MUC6 and focally positive for MUC1. ${ }^{92}$

The tubulopapillary-type (ITPM) is the most recently defined type of IPMN. Compared with other IPMNs, there is no macroscopically or microscopically detectable mucin, the growth pattern is solid with multiple well-circumscribed neoplastic nodules, two-thirds have high-grade dysplasia with invasive cancer, and they do not present the sequential progression usually seen with intestinal type. Immunohistochemically, the cells of the tubulopapillary-type (ITPM) are MUC6-positive and focally MUC1-positive. ${ }^{93}$

The molecular alterations seen in IPMN are similar to those seen in PDAC, including K-ras, p16/CDKN2A, SMAD4 and TP53, but at a lower frequency. For example K-ras mutations tend to occur early, and TP53 mutations occur in patients with more advanced disease, with 9.1\% of intermediate-grade IPMNs, $38.1 \%$ of high-grade IPMNs and 75\% of invasive cancer associated with TP53 mutations, and none seen in low-grade IPMNs. ${ }^{94}$ K-ras (17\% vs 58\%) and TP53 mutations (11\% vs 58\%) occur less frequently in oncocytic type of IPMN than the pancreaticobiliary type, possibly accounting for the lower rates of invasion, nodal metastases and better outcomes in oncocytic compared with pancreaticobiliary type IPMN. ${ }^{95}$ It has been recently noted that over 96\% of all IPMNs have either a GNAS or KRAS mutation, with more than half having a mutation in both. ${ }^{19,96}$ The GNAS gene encodes a $G$ protein alpha subunit ( $G$ alphas or $\mathrm{Gs} \alpha$ ), which is a ubiquitously expressed signal transducer that transmits hormonal and growth factor signals to effector proteins. A specific GNAS mutation hotspot (codon 201) is seen in IPMN, but not conventional PDAC, suggesting it is driving an IPMN specific pathway. ${ }^{19,96}$ GNAS mutations tend to be seen more commonly in the intestinal subtype of IPMN (up to $100 \%$ of all intestinal IPMNs in one study) and K-ras mutations are seen more commonly in the pancreaticobiliary subtype. ${ }^{97}$ However, the presence of multiple K-ras and GNAS mutations in a single patient support the concept of the polyclonal origin of IPMNs, and that multifocal IPMNs are independent lesions, supporting the role for continued surveillance of the remaining pancreas after partial resection for IPMN, in order to identify early new independent lesions. ${ }^{98}$ Less common mutations in IPMN include PIK3CA and BRAF.

Loss of expression of tumor suppressor genes, including p16/ CDKN2, CDKN1C and ppENK, due to hypermethylation, is seen at a greater rate in IPMN compared with PDAC, with increasing number of hypermethylated loci with higher grades of IPMN dysplasia. ${ }^{99,100}$ Evolving data suggests a role for microRNA (miRNA), small noncoding RNA molecules that function in the post-transcription regulation of gene expression in the pathogenesis of IPMN. Certain miRNAs, including miR-155, -21, and -122 , have been reported to be upregulated in most noninvasive IPMN, with increased overexpression in high-grade IPMNs. ${ }^{101-103}$

The exact etiology of IPMNs is unclear. However there does appear to be a genetic component. The familial predisposition to pancreatic cancer is associated with the development of IPMNs, with the frequency of IPMNs detected in patients with familial pancreatic cancer ranging from $10 \%$ to $18 \% .{ }^{77,89}$ A familial form of IPMN involving three generations without a history of familial pancreatic cancer, and no alterations in BRCA2, p16 or CDKN2A, has been reported. ${ }^{104}$

\section{Main-duct IPMN}

Main and combined type IPMN occur more frequently in men throughout the world, but the male-to-female ratio is highest in Asia (3:1). ${ }^{105}$ In one large series, the median age at diagnosis was 66 years, with a range of 31 to 87 years. ${ }^{75}$ The most common presenting symptom is abdominal pain (55\%), followed by weight loss (45\%), jaundice (17\%), and acute pancreatitis (15\%); in about $17 \%$ of cases, the diagnosis is made incidentally. ${ }^{75}$ In two-thirds of cases, the tumor is located in the proximal pancreas (i.e., head), and in 8\% it affects the entire gland. Radiologically, there is dilation of $>6 \mathrm{~mm}$ of the main pancreatic duct, often extending into secondary branches. Solid components can be observed within the lumen or duct wall, as well as calcifications, and the pancreas can be either enlarged or appear atro- 
phic. ${ }^{70}$ Endoscopically, a bulging papilla extruding mucus can be seen in about a third of cases of MD-IPMN, and is considered pathognomonic of this entity. This feature tends to be more consistently seen in advanced stages of the disease, being found in 73\% of patients with carcinoma-in-situ or invasive cancer, but only 39\% of patients with hyperplasia and adenoma. ${ }^{106}$ In advanced cases, IPMN can create fistulas with adjacent organs such as the stomach, duodenum and bile duct. ${ }^{107}$ In these circumstances, it is important to differentiate a primary fistula due to mechanical pressure from frank neoplastic invasion. Over time, the pancreatic acinar parenchyma surrounding and retrograde to the MD-IPMN can be replaced by fibrous tissue due to obstructive pancreatitis from a long-standing ductal obstruction.

ERCP can often visualize the filling defects from the tumors or mucus, and allows for brushings and fluid aspiration, and if pancreatoscopy is done it can sometimes visualize the papillary or villous growths. EUS demonstrates the dilated pancreatic duct and provide morphologic detail of the solid components within it, and allows for targeted biopsies. ${ }^{70}$ The treatment is surgical resection. It is very important to localize the tumor well preoperatively (often difficult because the entire ductal system is dilated), and liberal use of frozen section margins and intraoperative pancreatoscopy and/or ultrasound is recommended to ensure no tumor with high-grade dysplasia or worse is left behind..$^{70}$ Not infrequently, elderly patients are diagnosed and have had a history of recurrent pancreatitis that can go back 20 years or more. The consequences of a pancreatic resection in these elderly or frail individuals need to be weighed carefully against the perceived benefit.

\section{Branch-duct IPMN}

BD-IPMNs account for the majority of the increasingly recognized asymptomatic incidental pancreatic cysts. ${ }^{2}$ They can occasionally be symptomatic, including presenting with pancreatitis. Imaging features of BD-IPMNs range from an isolated subcentimeter pancreatic cyst to larger multi-centimeter solitary collections of pancreatic cysts. With improved imaging and pathologic assessment, BD-IPMNs can now also be recognized as a diffuse multifocal disease with $21 \%$ to $41 \%$ of patients having multiple BD-IPMNs (>2) of varying sizes scattered through their pancreas. ${ }^{77}$ This "field defect" has implications not only for diagnosis but also for postoperative surveillance; unlike MCN, surveillance of the residual pancreas after resection of a noninvasive BD-IPMN is required due to the risks of progression of residual BD-IPMNs, and the development of new BD-IPMN and concomitant PDAC. ${ }^{77}$

\section{1) BD-IPMN and risk of malignancy}

BD-IPMNs are all considered premalignant, but the risk can vary based on the size, associated worrisome features (e.g., nodules), multiplicity, and the underlying epithelial subtype. The

Table 2. Outcomes for Surveillance of Presumed BD-IPMN (Modified from Farrell et al. ${ }^{77}$ )

\begin{tabular}{|c|c|c|c|c|c|}
\hline Study & Year & No. & Follow-up, mo & Imaging progression (\%) & Malignancy/surgery (\%) \\
\hline Kobayashi & 2005 & 47 & 41 & $1(2)$ & $0 / 1(0)$ \\
\hline Carbognin & 2006 & 36 & 27 & $2(5)$ & $0 / 1(0)$ \\
\hline Levy & 2006 & 31 & 60 & 0 & 0 \\
\hline Salvia & 2007 & 89 & 32 & $5(6)$ & $0 / 5(0)$ \\
\hline Lee & 2007 & 45 & 27 & $10(22)$ & $1 / 10(10)$ \\
\hline Pelaez-Luna & 2007 & 81 & 41 & $11(14)$ & 1/11 (9) \\
\hline Salvia & 2007 & 131 & 40 & $1(2.5)$ & $1 / 1(100)$ \\
\hline Tanno & 2008 & 61 & 61 & $4(5)$ & $1 / 4(25)$ \\
\hline Ratou & 2008 & 121 & 33 & $12(10)$ & 4/8 (50) \\
\hline Pausawasdi & 2009 & 97 & 44 & NA & 2/22 (9) \\
\hline Woo & 2009 & 124 & 41 & $7(6)$ & 2/19 (11) \\
\hline Sawai & 2010 & 103 & 59 & $29(28)$ & $6 / 11(54)$ \\
\hline Kang & 2011 & 201 & 28 & 39 (19) & 8/35 (23) \\
\hline Uehara & 2011 & 100 & 97 & $5(5)$ & 1/1 (100) \\
\hline Khannoussi & 2012 & 53 & 84 & $15(28)$ & $2 / 3(67)$ \\
\hline Maguchi & 2012 & 349 & 44 & $62(17.8)$ & 9/22 (40) \\
\hline Ohno & 2012 & 142 & 42.5 & $30(21)$ & 9/30 (30) \\
\hline Cauley & 2012 & 244 & 35 & 30 (12) & 2/28 (7) \\
\hline Bae & 2012 & 152 & 12.7 & $18(12)$ & 1/18 (5) \\
\hline Total & - & 2,207 & - & - & $50 / 228$ \\
\hline
\end{tabular}

BD-IPMN, branch-duct intraductal papillary mucinous neoplasm. 
mean frequency of malignancy (defined as high-grade dysplasia and invasive cancer) in surgically resected BD-IPMN is $25.5 \%$ (range, 6.3\% to 46.5\%) and the mean frequency of invasive cancer $17.7 \%$ (range, $1.4 \%$ to $36.7 \%$ ). ${ }^{23}$ However, in surveillance studies of presumed BD-IPMNs, the actuarial risk of developing cancer has been reported as high as 20\% over a 10-year period (about 2\% per year), although other estimates are lower (Table 2). ${ }^{77}$ Estimates of cancer risk are compounded by Japanese investigators reporting the development of concomitant PDAC independent from BD-IPMNs within the pancreas. ${ }^{77}$ In one study of 183 resected invasive cancers seen in patients with IPMN, 66\% were classified as PDAC derived from IPMN and 17\% as PDAC concomitant with IPMN. These findings support the concept of a pancreas "field defect" which may give rise to both IPMN and PDAC, and the importance of carefully reviewing the entire pancreatic parenchyma in addition to the cyst. ${ }^{108}$ One study suggested that the BD-IPMNs associated with concomitant PDAC were predominantly of the gastric subtype. ${ }^{109}$

\section{2) Clinical evaluation of presumed BD-IPMN}

Diagnosis and cancer-risk stratification are the two main clinical challenges for BD-IPMN. While the presence of multiple pancreatic cysts in the setting of a normal pancreatic duct is strongly suggestive of a multifocal BD-IPMN, the presence of a solitary pancreatic cyst of any size is a diagnostic challenge. The presence of ductal communication on MRI may favor a BDIPMN over an MCN, but this is not always seen; and a clinical history of pancreatitis may be seen with both a solitary pseudocyst and BD-IPMN. Although additional imaging with EUS with identification of ductal communication, internal significant nodules, and elevated cyst fluid CEA level may be helpful, often one is left managing patients with presumed BD-IPMNs in the absence of a definite diagnosis. This difficulty in preoperative diagnosis is highlighted by a recent study demonstrating that even for patients undergoing surgery for presumed BD-IPMN, many had main pancreatic duct involvement or an alternate diagnosis on pathologic review. ${ }^{110}$

\section{3) Guidelines for management of presumed BD-IPMN}

For patients with a definite diagnosis of a BD-IPMN or those with a strong suspicion of a presumed BD-IPMN, the next major challenge is risk-stratification for cancer development, a crucial determinant of either operative or nonoperative (surveillance) management. The original Sendai guidelines published in

Are any of the following high-risk stigmata of malignancy present?

(1) Obstructive jaundice in a patient with cystic lesion of the head of the pancreas, (2) enhancing solid component within cyst, (3) main pancreatic duct $\geq 10 \mathrm{~mm}$ in size

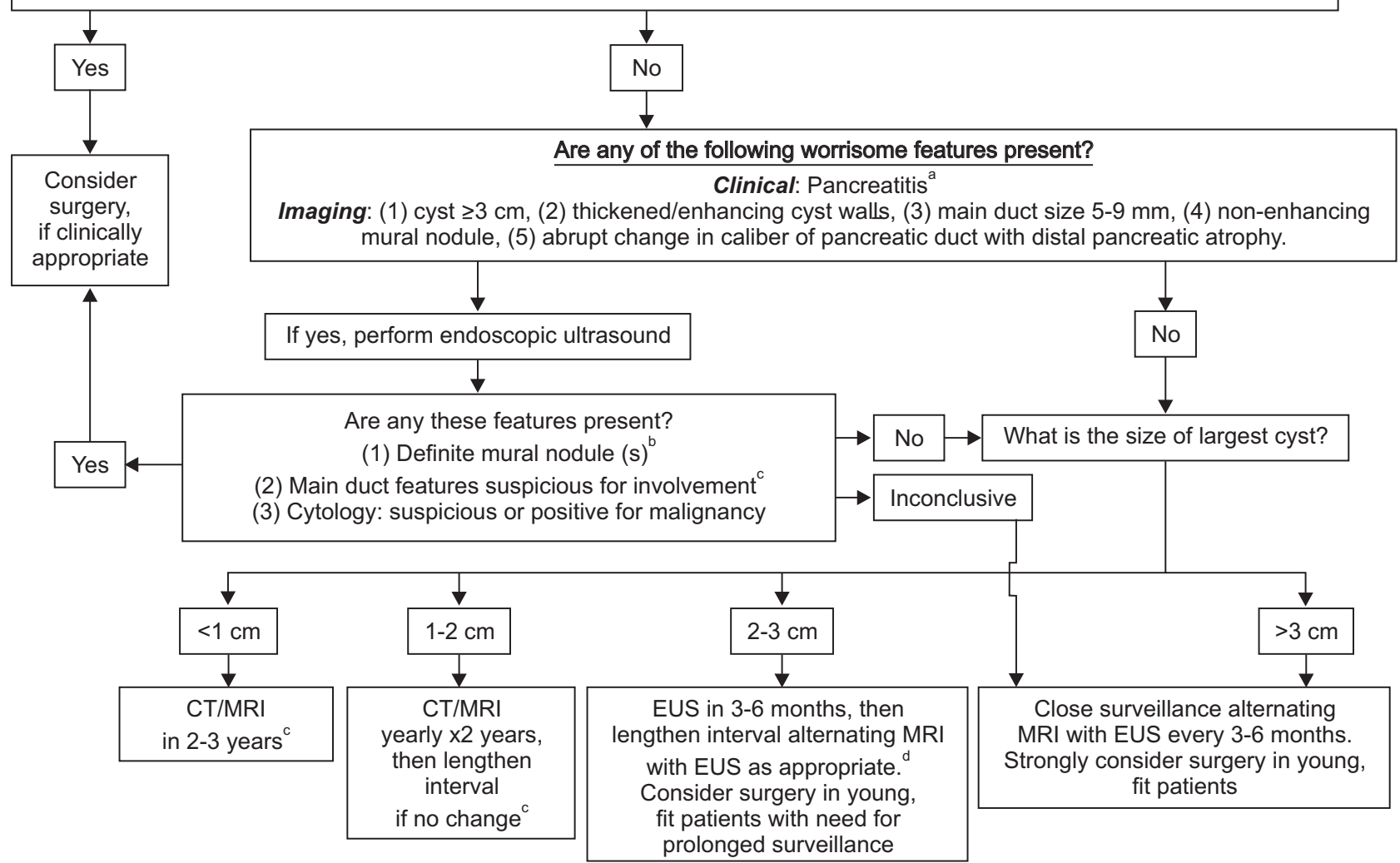

Fig. 1. The Fukuoka guidelines for the management of presumed BD-IPMN and MCN.

BD-IPMN, branch-duct intraductal papillary mucinous neoplasm; MCN, mucinous cystic neoplasm; CT, computed tomography; MRI, magnetic resonance imaging, EUS, endoscopic ultrasound. 
2006 suggested that for patients with definite or presumed BDIPMN, cysts greater than $3 \mathrm{~cm}$, or for cysts less than $3 \mathrm{~cm}$ with symptoms, a dilated main pancreatic duct greater than $6 \mathrm{~mm}$, or nodule, surgical resection is indicated. ${ }^{111}$ The remainder can be managed nonoperatively with routine surveillance. Evaluation of these original Sendai guidelines on retrospectively collected surgical BD-IPMN patients showed a low positive predictive value (PPV) of $20 \%$, meaning that for every five surgical resections, only one patient had an advanced lesion; and whereas initial studies suggested a high negative predictive value, meaning no cancers are missed, more recent studies have questioned this finding. ${ }^{77,112-116}$ The personalization of recommendations for surgery for presumed BD-IPMNs needs take into account several additional factors, including age of patient, overall medical condition, operative risk and location of the cyst. It has been suggested that for younger patients ( $<65$ years), a threshold of $2 \mathrm{~cm}$ may be used to determine surgical resection due to the cumulative effect of cancer risk during the patients' lifetime. ${ }^{117}$ Since a size of BD-IPMN $>3 \mathrm{~cm}$ is a weaker indicator of malignancy than the presence of mural nodule and positive cytology, BD-IPMN greater than $3 \mathrm{~cm}$ without these signs can be observed without immediate resection, particularly in elderly patients. ${ }^{118}$ A Fukuoka guideline was recently published giving more specific updated recommendations for surgical resection and surveillance (Fig. 1). These newer guideline's operating characteristics in the clinical setting needs to be further validated prospectively. ${ }^{23}$

\section{4) Multifocal BD-IPMN}

Up to 25\%-41\% of all BD-IPMNs are multifocal (>2 lesions) and with increasing experience, guidelines for the management of these multifocal BD-IPMN are being established. ${ }^{77}$ Large surgical series suggest that multifocal BD-IPMN may represent a lower risk BD-IPMN than solitary BD-IPMN, and decisions about surgery and surveillance should be made on an individual cyst basis rather than on the whole collective cysts. ${ }^{77}$ Partial pancreatectomy is the preferred method of treatment for disease confined to just one area of the pancreas, or of the area deemed to be at highest risk of developing, with surveillance of the residual pancreas. Rarely, a total pancreatectomy is necessary. ${ }^{119}$

\section{5) Surveillance strategies}

With the accepted low but persistent risk of malignancy in the majority of BD-IPMNs, the role of surveillance in the nonoperative management of presumed BD-IPMNs has been further refined. In the cumulative series of surveillance for presumed BD-IPMN, the surgical intervention rate is $<10 \%$ and the risk of finding an associated malignancy is $<5 \%$, suggesting that the overall risks are very low even in these highly selected surveillance patients. ${ }^{77}$ In addition to the level of anxiety this surveillance can cause patients, it also represents a huge economic cost, without evidence of improved long-term outcome or qual- ity of life. It is generally agreed that MRI/magnetic resonance cholangiopancreatography (MRCP) is the preferred method of surveillance (over CT), due to enhanced ability to see nodules and ductal communication, but also due to reduced radiation exposure over time. ${ }^{120}$

The exact interval of surveillance is unclear. For surveillance, patients without high-risk stigmata, as defined by new Fukuoka guidelines (symptoms/signs related to IPMN, presence of mural nodules, dilation of the main pancreatic duct [>10 $\mathrm{mm}$ ] or positive pancreatic juice cytology), should undergo a short interval (3 to 6 months) pancreatic MRI-MRCP (or CT) to establish stability, followed by annual surveillance. ${ }^{23}$ Concerns over the development of concomitant PDAC in the pancreas harboring IPMN has prompted some investigators to continue surveillance at close intervals. ${ }^{120}$ However, for subcentimeter cysts, surveillance every 2 to 3 years seems reasonable. ${ }^{120}$

Patients with high-risk stigmata detected on surveillance, if fit, should undergo resection. Shorter interval surveillance (3 to 9 months) should be considered in patients whose IPMN progresses towards these indicators or who already have high-risk stigmata and for reasons of operative risk or personal preference have chosen heightened surveillance over resection. ${ }^{23}$ Shorter interval surveillance should also be performed for IPMN patients with a family history of hereditary PDAC (i.e., >1 first degree relatives with PDAC), although whether these patients are susceptible to more aggressive IPMNs remains unclear. ${ }^{121}$ Whether rapid growth rate correlates with increased risk of malignancy is also not known, but closer surveillance including use of EUS is recommended in such patients. ${ }^{122}$ For patients undergoing surgical resection for noncancerous BD-IPMNs, the overall prognosis is excellent, but these patients are always at risk of developing significant metachronous cysts in the remaining pancreas, as well as concomitant PDAC, necessitating ongoing postoperative surveillance. ${ }^{52,123}$

One controversial question with surveillance is when to stop surveying patients with presumed BD-IPMNs. It makes no sense to survey when a patient is not a good surgical candidate. Arbitrarily, a patient 85 years old is used, but it is really a function of the patient's overall medical condition. The concept of stopping surveillance for a small cyst which shows stability after 2 years, in any age group, has been also suggested by the American College of Radiology, but there is no good long-term data to support this approach. ${ }^{120}$ The notion of stopping surveillance of BD-IPMN is countered by anecdotal stories of patients with chronically stable presumed BD-IPMN that grow and develop cancer after long periods of stability, and the persistent risk of the development of concomitant PDAC in patients with a history of IPMN. ${ }^{77,124}$

\section{OTHER RARE CYSTIC NEOPLASMS}

Lymphoepithelial cysts of the pancreas are rare lesions com- 
prising $0.5 \%$ of all pancreatic cysts, seen in middle-aged men. The average size at presentation is $6 \mathrm{~cm}$ (range, 1 to more than $15 \mathrm{~cm})$. These cysts are mostly multiloculated or unilocular with septations, often contain focal calcification, and typically involve the tail. ${ }^{125}$ Lymphoepithelial cysts are considered true cysts, since they are lined by stratified squamous epithelium and surrounded by mature lymphocytes. A variety of theories exist about the origin of lymphoepithelial cysts including squamous metaplasia of an obstructed intrapancreatic duct, which subsequently protrudes into a peripancreatic lymph node; the development from ectopic pancreatic tissues in the peripancreatic lymph nodes; or misplaced branchial cleft cysts. These cysts can be difficult to preoperatively differentiate from other pancreatic cysts such as true cystic neoplasms and pseudocysts, and so avoid surgical diagnosis. On CT and MRI imaging, lymphoepithelial cysts are more often seen as extrapancreatic compared with other pancreatic cysts. In-phase and out-of-phase MRI scans can greatly distinguish lymphoepithelial cysts from other cystic lesions of the pancreas. On EUS and EUS-guided FNA (EUS-FNA), lymphoepithelial cysts typically appear as hypoechoic cystic lesions which are either unilocular or multilocular, with intracystic hyperechoic debris internally seen rarely. EUS-FNA aspirate showing squamous epithelial materials rich in lymphocytes strongly support the diagnosis of lymphoepithelial cyst. ${ }^{126}$ Despite these imaging and biopsy features, surgical excision with pathological examination is still often used to confirm the diagnosis.

Cystic lymphangioma of the pancreas is a rare benign neoplasm, which is typically discovered incidentally in asymptomatic individuals. Lymphangiomas are benign lesions that originate from lymphatic vessels and occur most commonly in children. Histologically, pancreatic cystic lymphangiomas consist of interconnecting cysts separated by septa, lined by epithelial cells, and contain serous, serosanguineous, or chylous fluid. ${ }^{127}$ EUS imaging of pancreatic cystic lymphangiomas can be similar to mucinous lesions of the pancreas, but the diagnosis of pancreatic cystic lymphangioma is made if the aspirated fluid is chylous in appearance and has an elevated triglyceride level. If the fluid aspirated is serous and only has a mildly elevated triglyceride level, then it may be difficult to differentiate from other pancreatic cystic neoplasms. ${ }^{128,129}$ Solid pancreatic tumors may present with cystic degeneration. PDAC rarely undergoes cystic degeneration, up to $1.6 \%$ in one series. Typically PDAC grows to a large size (mean of $7 \mathrm{~cm}$ ) before undergoing cystic degeneration. ${ }^{130}$

\section{ROLE OF IMAGING, EUS AND CYST FLUID ANALYSIS IN THE DIAGNOSIS AND MANAGEMENT OF CYSTIC NEO- PLASMS OF THE PANCREAS}

Before evaluating a CNP with EUS and EUS with FNA and cyst fluid aspiration, the likely impact of this intervention on diagnosis, management and patient outcome needs to be considered. This is best done in a multidisciplinary setting, after discussion of the patient's presentation and operative risk, as well as expert review of high-quality CT or MR examinations. ${ }^{131}$

CT and MRI alone can be useful in the diagnosis and management of CNP when the classic features of certain CNPs are present. For example, a microcystic pancreatic lesion with a central stellate calcification on CT imaging is pathognomonic of a benign serous cystadenoma; a tortuous dilated main pancreatic duct with associated cysts is suggestive of a main duct IPMN; and multiple diffuse pancreatic cysts associated with a normal caliber main pancreatic duct is likely multifocal BDIPMN. However, CT (accuracy, 24\% to 61\%) and MRI (accuracy, $74 \%$ ) alone can be insensitive in correctly identifying the type of pancreatic cyst in studies comparing the preoperative imaging diagnosis with surgical pathology. ${ }^{27,29,31,132}$ Whereas high resolution CT using thin sections provides detailed information and may provide a presumptive diagnosis if pathognomonic features, are present, MRI/MRCP has the advantage of providing clear imaging of the pancreatic duct, defining the relationship between the pancreatic duct and the cyst, without the associated ionizing radiation. Compared with CT, MRI has the ability to diagnose additional small pancreatic cysts which might support the diagnosis of IPMN. ${ }^{89}$

\section{EUS imaging}

However there are several CT and MRI findings of CNPs where the diagnosis and the risk of associated malignancy are unclear. For example, a multiple macrocystic pancreas lesion in the body and tail of the pancreas may represent a benign macrocystic serous cystadenoma, or a premalignant mucinous lesion such as an MCN or a BD-IPMN. ${ }^{21}$ In fact, the isolated single pancreatic cyst of any size seen on CT or MRI remains the most challenging clinical problem, especially in the absence of pancreatitis; with the differential including a BD-IPMN, a benign pseudocyst and more worrying solid degeneration of a solid neoplasm such as a pancreatic ductal adenocarcinoma or an endocrine neoplasm. Studies have shown the difficulty high quality CT or MRI imaging has in distinguishing mucinous from nonmucinous pancreas lesions. ${ }^{77}$ Despite being an operator dependent invasive imaging modality, EUS's clear additive strengths compared with CT or MRI are superior higher resolution imaging of the pancreas (to detect ductal communication, additional cyst, nodules and associated masses) and the ability to sample the cyst contents for cytologic and fluid analysis.

EUS of the pancreas can often detect a communication between a pancreatic cyst and a normal main pancreatic duct, suggesting a diagnosis of a BD-IPMN, although this finding is not always present and can also be seen in patients with pseudocyst. When prospectively compared with high quality MRI of the pancreas and MRCP, however, both EUS and MRI are equivalent at detecting pancreatic cyst-main duct communica- 
tion. ${ }^{133}$ Sometimes, MRI or CT imaging raises concern about involvement of the main pancreatic duct in the CNP, suggesting a possible mixed or main duct IPMN rather than a BD-IPMN. This important distinction can be clarified using EUS rather than a diagnostic ERCP pancreatogram, which is not routinely recommended in the evaluation of CNPs.

The presence of multiple pancreatic cysts on CT or MRI imaging favors an underlying diagnosis of a multifocal type BDIPMN. EUS's superior imaging can certainly detect smaller cysts throughout the pancreas, which would support this diagnosis. However in prospective studies comparing high quality CT, MRI and both linear and radial EUS for the identification of pancreatic cyst, MRI and EUS are equivalent and vastly superior to CT for the detection of smaller additional cysts. ${ }^{77}$

The presence of nodules on surgically resected BD-IPMNs is associated with increased risk of advanced pathology (high-grade dysplasia or invasive cancer) on those specimens. In one study, $3 \%$ of BD-IPMN with low- or intermediate-grade dysplasia had a nodule on pathologic review compared with $60 \%$ of BD-IPMN with high-grade dysplasia or carcinoma. ${ }^{77}$ Interestingly, none of the patients with low-grade dysplasia had evidence of a nodule on pathologic examination, and on occasion, the significant advanced pathology finding of either high-grade dysplasia or invasive cancer was remote from the nodule in the cyst. In addition, not all nodules detected are even precancerous. For example, the nodules seen in lymphoepithelial cysts are keratinizing squamous pearls, and mucin globules account for a large percentage of "nodules" seen on imaging of IPMN cysts.

Hence, the importance of finding and characterizing CNP mural nodules on preoperative imaging. Although the definitions governing mural nodules on CT/MRI and EUS imaging lack standardization in the literature, a meta-analysis suggests that finding a mural nodule on CT or MRI imaging of presumed BD-IPMN is associated with an increased risk of advanced pathology (high-grade dysplasia/invasive pathology) (odds ratio [OR], 9.3; 95\% confidence interval [CI], 5.3 to 16.1). However when looking just mural nodules identified soley by EUS, the risk of an advanced pathology is lower (OR, 3.2; 95\% CI, 2.03 to 5.04). This discrepancy is likely related to the over-diagnosis of nonpathologic "mucin" globule by EUS. ${ }^{77}$ On EUS, mucin globules are hypoechoic with a smooth edge and hyperechoic rim, and move with patient repositioning or EUS-FNA. Using a pathologic gold standard and endosonographer trained to distinguish mucin globules from real nodules, a recent study showed that EUS was more sensitive than CT in detecting significant cystic nodules. ${ }^{77}$ Although it has been proposed that finding a pathologic nodule in a cyst on EUS should favor surgical management, it is unclear if there is a nodule size threshold, below which surgery could be avoided. Data supports surveying patients with large presumed BD-IPMN greater than $3 \mathrm{~cm}$ who do not have nodules; ${ }^{118}$ and it has also been suggested that presumed small MCNs (unilocular, pancreatic body/ tail location, female gender, middle age, elevated cyst fluid CEA) without nodules on EUS can be surveyed closely without operative intervention.

\section{EUS and pancreatic cyst fluid analysis}

The other major strength of EUS in the evaluation of CNP, when compared with CT or MRI, is the ability to safely perform cyst fluid aspiration and analysis of cytology and tumor markers. ${ }^{134}$ Whereas the specificity for EUS-FNA cytology is close to $100 \%$, it has a very poor sensitivity (30\% to 50\% for detecting mucinous cysts, and 20\% for the diagnosis of a malignant mucinous cysts). This is due to a combination of factors including poor cellular yield, insufficient samples, and gastrointestinal wall cellular contamination. ${ }^{77,135}$ Although a variety of strategies have been used to improve on this, including targeting FNA biopsy, the use of brush cytology, different sample preparation, and the use of cytopathology expertise, the results remain poor. One additional strategy has been to "lower the bar" and include high-grade atypical epithelial cells (which recognizes epithelial cells with cellular atypia that is quantitatively and qualitatively insufficient for a definite cancer diagnosis) as a positive diagnosis. When these criteria are used, the accuracy is increased to $85 \%$. $^{135}$

The role of existing and newer pancreatic cyst fluid markers continues to be evaluated. The real benefit of measuring cyst fluid CEA is in differentiating mucinous from nonmucinous pancreatic cysts. For example, a very low CEA $(<5 \mathrm{ng} / \mathrm{mL})$ carries a PPV of 94\% and an accuracy of 70\% for diagnosing a serous cystadenoma or pseudocyst over a mucinous CNP. Similarly a very high CEA (>800 ng/mL) carries a PPV of 94\% and an accuracy of 79\% for diagnosing a mucinous CNP over a serous cystadenoma or a pseudocyst. ${ }^{136}$ However, the exact cutoff for pancreatic cyst fluid CEA level for distinguishing mucinous from nonmucinous lesions remains unclear. In the prospective pancreatic cyst co-operative study, a cutoff of $192 \mathrm{ng} / \mathrm{mL}$ was associated with an accuracy of 80\% in distinguishing mucinous from nonmucinous, the best operating characteristic of any fluid marker or cytology in that particular study. ${ }^{22}$ More importantly, pancreatic cyst fluid CEA level does not correlate with the risk of malignancy. Even though very high levels of cyst CEA $(>6,000$ $\mathrm{ng} / \mathrm{mL}$ ) were seen in patients with malignant mucinous lesions in one study, the absolute level of the CEA was not a greater predictor of cancer, the development of cancer over time, or the increase in cyst size over time. ${ }^{22,137}$ Pancreatic cyst fluid CEA level can therefore be helpful in evaluating macrocystic lesions of the pancreas where the differential diagnosis includes a benign macrocystic serous cystadenoma (very low CEA level and associated satellite microcysts) and a precancerous mucinous cystic neoplasm (high CEA, unilocular cyst in body tail of the pancreas with internal septations), or a precancerous BD-IPMN (high CEA, communication with the main pancreatic duct). ${ }^{21}$

Molecular DNA analysis of pancreatic cyst fluid is now also 
available commercially. However one multi-institutional prospective study (the PANDA study) and several retrospective, single institutional studies, have failed to convincingly show its defined role. ${ }^{41,77,138-146}$ Whether the presence of a K-ras mutation, the presence of allelic imbalance, or the quantity/quality of DNA is used, alone or in combination with CEA, to differentiate between mucinous or nonmucinous cysts, or between benign or malignant pancreatic cysts, the operating characteristics of these molecular analysis remains poor with low sensitivity and specificity. $^{77}$

The prospective evaluation of both pancreatic cyst fluid CEA and molecular analysis is further compounded by the apparent lack of applicability of the results from these studies to patients typically seen in regular clinical practice. In both the Pancreatic Cyst Cooperative Study and the PANDA study, 35\% to 43\% of the patients had a final diagnosis of a malignant cyst, which is much higher than would expect in a regular patient population. Furthermore, the types of pancreatic cyst which gastroenterologists need most help with, were not represented well in these studies. For example, the number of patients with cysts less than $2 \mathrm{~cm}$ ranged from $27 \%$ to $40 \%$ of the entire study group, and for those with a final mucinous pathology only $29 \%$ to $40 \%$ were less than $2 \mathrm{~cm}$ in size. Re-evaluation of the operating characteristic of these markers is needed in the patient population which gastroenterologist and surgeons in community practice typically see and have the greatest difficulty in managing. ${ }^{77}$ Additional validation of newer pancreatic cyst fluid markers such as GNAS or miRNA may assist in improved diagnosis and cancer risk prediction, as well as further refining stratification for patients in pancreatic cyst surveillance programs. ${ }^{77,102,139}$

\section{Therapeutic EUS}

EUS-guided ablation of pancreatic cysts, with either ethanol or ethanol followed by paclitaxel for large unilocular cyst without obvious ductal communication or high-risk pancreatic cysts where the patient refuses surgery or is considered too high risk, has been proposed. ${ }^{147-152}$ Although associated with complications including pancreatitis ( $2 \%$ to $10 \%$ ), abdominal pain ( $2 \%$ to $20 \%$ ) and splenic vein obliteration, follow-up for these patients does show CT-confirmed resolution of the cysts. ${ }^{153}$ Information about degree of cyst ablation is available on a smaller number of patients who underwent surgical resection, where complete cyst epithelial ablation occurred in between $0 \%$ and 100\% of patients. However, due to concerns about incomplete destruction of premalignant tissue, uncertainty about impact on natural history of CNPs, persistent risk of concomitant PDAC, and lack of long-term outcomes, this approach is still considered experimental and should be performed under a research protocol.

\section{Which patients with CNP benefit from EUS?}

After expert multidisciplinary discussion and review of CT or MRI imaging, can we determine which patients benefit from further EUS evaluation? Patients with solitary subcentimeter or multiple subcentimeter pancreatic cysts in the setting of a normal pancreatic duct are unlikely to benefit from additional EUS evaluation, as the likely diagnosis here is a BD-IPMN, with the chances of having a cancer or developing an invasive cancer before the next interval noninvasive surveillance being very low. ${ }^{77}$ For patients with the classic radiologic features of a microcystic serous cystadenoma, including a central stellate scar, the addition of EUS rarely alters diagnosis, management or outcome. Rarely, the CT/MR and even EUS imaging of a microcystic serous cystadenoma can be mistaken for a solid pancreatic endocrine neoplasm. ${ }^{154,155}$ This can be a good indication for an EUS-guided core biopsy to confirm the diagnosis. ${ }^{155}$

EUS has select benefit in other patients with CNP. As previously mentioned, if the clinical presentation and imaging raises concerns about differentiating between a macrocystic serous cystadenoma and a mucinous neoplasm (MCN or BD-IPMN), then EUS and cyst fluid aspiration may be helpful. When multidisciplinary evaluation and expert review of high quality CT and MR raises the possibility of a solid component or focal or diffuse main duct involvement of a solitary cyst, then EUS can help clarify these finding and enhance the diagnostic certainty. This can be especially important in patients with chronic pancreatitis or recurrent acute pancreatitis, where focal or diffuse main duct abnormalities may represent main duct IPMN rather than the features of chronic pancreatitis. EUS may also be useful in the select evaluation of patients with presumed BD-IPMN greater than $3 \mathrm{~cm}$. Although current guidelines would favor surgical management based on size alone, for patients who are elderly, poor operative candidates or just reluctant to undergo surgery in the absence of a more definite diagnosis of highgrade dysplasia or invasive cancer, the lack of nodules on EUS in cysts greater than $3 \mathrm{~cm}$ may help determine a subgroup of patients with presumed BD-IPMN who are suitable for close surveillance rather than surgery.

EUS has a definite role for patient with solitary or multifocal cysts between the sizes of 1 and $3 \mathrm{~cm}$, especially those without worrisome features on CT or MRI imaging, although the newer Fukuoka guidelines question the value of EUS for cyst less than $2 \mathrm{~cm}$ without worrisome features. Most of these are presumed to be single or multifocal BD-IPMN and are typically managed with surveillance in the absence of worrisome features on CT or MRI imaging. Prior to initiating a long-term, noninvasive surveillance strategy which may include MRI or CTs every 1 to 2 years, a single EUS can be helpful to rule out associated masses (e.g., CPEN), assess for internal nodules and check a cyst fluid cytology and CEA to confirm the diagnostic suspicion of a mucinous cyst. In a surveillance program, imaging with EUS may prove to be useful for cysts, which are increasing in size to rule out an associated malignancy. ${ }^{77}$ Although there is limited data, a rapid increase in cyst size has been associated with increased risk of advanced pathology. The propensity for benign serous 
cystadenomas to increase in size must be considered and EUS may be able to differentiate these two entities. ${ }^{77}$

\section{SURGICAL TREATMENT}

Surgical resection is the treatment of choice for symptomatic patients with cystic neoplasms of the pancreas and for those with incidentally-discovered tumors that are deemed to have a high likelihood of malignancy (i.e., mucinous cystic neoplasms, CPEN, solid pseudopapillary neoplasm, and main- [and combined-] duct IPMN). The type of resection depends on the location of the lesion. In a recent series comprising 851 resected cystic tumors, 44\% required a distal pancreatectomy, 43\% a pancreatoduodenectomy (Whipple procedure), 7\% a middle pancreatectomies (where the end of the pancreas towards the duodenum is closed, and the one coming from the tail is anastomosed to either the stomach or jejunum), and the remaining were enucleations (usually reserved for small lesions with low risk of malignancy), other atypical pancreatic resections, and total pancreatectomies. ${ }^{10}$ The extent of pancreatic resection, especially for IPMN, should be guided by intraoperative frozen section examination until disease free margins are obtained. If high-grade dysplasia or invasive cancer are present at the surgical margin, then further resection is warranted. ${ }^{156}$ This and other series show that operative mortality when these operations are done in specialty centers can be kept under 1\%, but that complications still occur in over 40\% of patients. ${ }^{10,157}$ However, these results from high volume centers are likely to underestimate the overall rates of mortality and morbidity associated with pancreatic surgery for pancreatic cystic neoplasms. ${ }^{81}$ In many centers, laparoscopic resections, particularly distal pancreatectomies, are being increasingly used for cystic neoplasms of the pancreas. In addition to the morbidity of the operation, long-term sequelae of the loss of pancreatic parenchyma (e.g., diabetes, exocrine insufficiency, and effects on quality of life) need to be weighed carefully.

\section{Postoperative surveillance}

In the absence of histologic evidence of invasive cancer, patients with surgical resection of pancreatic cystic endocrine neoplasm, serous cystadenoma and mucinous cystic neoplasm, do not require additional surveillance. However, due to malignant risk of existing IPMNs and the 15\% to 25\% risk of developing new IPMNs in residual pancreas, all patients with proven IPMN should undergo surveillance, not just for existing or new IPMN, but also because of the increased risk of concomitant pancreatic ductal adenocarcinoma. Patients with invasive IPMN should be managed and surveyed as per PDAC guidelines. Patients with noninvasive IPMN should be surveyed based on the findings of the residual pancreas. The largest remaining cyst should dictate surveillance strategies per recent guidelines. For patients without cysts in the residual pancreas, then surveillance imaging at an interval of 2 years is recommended. For those, who in addition also had low-grade or moderate-grade dysplasia at the resection margin, more close surveillance imaging every 6 months is warranted.

\section{FUTURE DIRECTIONS}

\section{Multidisciplinary management}

The lack of accurate imaging and cyst fluid biomarkers, makes the precise management decisions for pancreatic cystic neoplasms (i.e., surgery vs surveillance) more difficult. This is supported by the high rates of resection of "benign" pancreatic cysts, as well as the development of incident malignancy on surveillance follow-up. ${ }^{158}$ Hence it is likely that the management of these patients will benefit from the consensus input of the various disciplines involved in their care: gastroenterology, surgery, pathology, radiology. The evolution of these multidisciplinary pancreas cysts clinics has the potential to alter diagnosis, management and overall outcome in this group of patients. $^{159-161}$

\section{Novel pancreatic cyst fluid biomarkers}

Due to the imperfect nature of pancreatic cyst fluid cytology and CEA, there is still a need for improved diagnostic and predictive cyst fluid biomarkers for pancreatic cystic neoplasms, both in differentiating mucinous from nonmucinous lesions, but for also assessing the degree of dysplasia. Two promising areas for biomarker development include mucins and miRNA.

Pancreas mucins (MUCs) are heavily glycosylated highmolecular weight glycoproteins, which play an important role in lubrication and protection of the pancreatic duct lining. Several human MUC genes exist and proteomic analysis may distinguish the different histopathologic subtype of IPMN. ${ }^{162}$ Cyst fluid MUC profiles could diagnose gastric subtype of IPMN (low MUC2, MUC4 and MUC5A) compared with nongastric subtypes, with higher levels of MUC2 and MUC4 levels clustering with degree of dysplasia. ${ }^{163}$ MUC7 RNA gene expression from EUSFNA biopsy was significantly associated with pancreatic ductal adenocarcinoma, and less so for IPMN. ${ }^{164}$

miRNAs are small noncoding RNAs which regulate the stability and translation of mRNA transcription. Elevated levels of miR-21 and miR-155 were found in surgical resection specimens to be associated with advanced degrees of dysplasia in IPMN. ${ }^{165}$ More recent data has suggested the elevated levels of miR-21 and miR-221 in pancreatic cyst fluid is also associated with advanced degrees of dysplasia. ${ }^{102}$

\section{CONFLICTS OF INTEREST}

No potential conflict of interest relevant to this article was reported. 


\section{REFERENCES}

1. de Jong K, Nio CY, Mearadji B, et al. Disappointing interobserver agreement among radiologists for a classifying diagnosis of pancreatic cysts using magnetic resonance imaging. Pancreas 2012;41:278-282.

2. Laffan TA, Horton KM, Klein AP, et al. Prevalence of unsuspected pancreatic cysts on MDCT. AJR Am J Roentgenol 2008;191:802807.

3. Girometti R, Intini S, Brondani G, et al. Incidental pancreatic cysts on 3D turbo spin echo magnetic resonance cholangiopancreatography: prevalence and relation with clinical and imaging features. Abdom Imaging 2011;36:196-205.

4. Zhang XM, Mitchell DG, Dohke M, Holland GA, Parker L. Pancreatic cysts: depiction on single-shot fast spin-echo MR images. Radiology 2002;223:547-553.

5. Matsubara S, Tada M, Akahane M, et al. Incidental pancreatic cysts found by magnetic resonance imaging and their relationship with pancreatic cancer. Pancreas 2012;41:1241-1246.

6. Lee KS, Sekhar A, Rofsky NM, Pedrosa I. Prevalence of incidental pancreatic cysts in the adult population on MR imaging. Am J Gastroenterol 2010;105:2079-2084.

7. Ip IK, Mortele KJ, Prevedello LM, Khorasani R. Focal cystic pancreatic lesions: assessing variation in radiologists' management recommendations. Radiology 2011;259:136-141.

8. Kimura W, Nagai H, Kuroda A, Muto T, Esaki Y. Analysis of small cystic lesions of the pancreas. Int J Pancreatol 1995;18:197-206.

9. Gardner TB, Glass LM, Smith KD, et al. Pancreatic cyst prevalence and the risk of mucin-producing adenocarcinoma in US adults. Am J Gastroenterol 2013;108:1546-1550.

10. Valsangkar NP, Morales-Oyarvide V, Thayer SP, et al. 851 resected cystic tumors of the pancreas: a 33-year experience at the Massachusetts General Hospital. Surgery 2012;152(3 Suppl 1):S4-S12.

11. Crippa S, Salvia R, Warshaw AL, et al. Mucinous cystic neoplasm of the pancreas is not an aggressive entity: lessons from 163 resected patients. Ann Surg 2008;247:571-579.

12. Yamao K, Yanagisawa A, Takahashi K, et al. Clinicopathological features and prognosis of mucinous cystic neoplasm with ovarian-type stroma: a multi-institutional study of the Japan pancreas society. Pancreas 2011;40:67-71.

13. Le Baleur Y, Couvelard A, Vullierme MP, et al. Mucinous cystic neoplasms of the pancreas: definition of preoperative imaging criteria for high-risk lesions. Pancreatology 2011;11:495-499.

14. Zamboni G, Scarpa A, Bogina G, et al. Mucinous cystic tumors of the pancreas: clinicopathological features, prognosis, and relationship to other mucinous cystic tumors. Am J Surg Pathol 1999;23:410-422.

15. Thompson LD, Becker RC, Przygodzki RM, Adair CF, Heffess CS. Mucinous cystic neoplasm (mucinous cystadenocarcinoma of low-grade malignant potential) of the pancreas: a clinicopathologic study of 130 cases. Am J Surg Pathol 1999;23:1-16.

16. Baker ML, Seeley ES, Pai R, et al. Invasive mucinous cystic neo- plasms of the pancreas. Exp Mol Pathol 2012;93:345-349.

17. Jimenez RE, Warshaw AL, Z'graggen K, et al. Sequential accumulation of K-ras mutations and p53 overexpression in the progression of pancreatic mucinous cystic neoplasms to malignancy. Ann Surg 1999;230:501-509.

18. Iacobuzio-Donahue CA, Wilentz RE, Argani P, et al. Dpc4 protein in mucinous cystic neoplasms of the pancreas: frequent loss of expression in invasive carcinomas suggests a role in genetic progression. Am J Surg Pathol 2000;24:1544-1548.

19. Wu J, Jiao Y, Dal Molin M, et al. Whole-exome sequencing of neoplastic cysts of the pancreas reveals recurrent mutations in components of ubiquitin-dependent pathways. Proc Natl Acad Sci U S A 2011;108:21188-21193.

20. Izumo A, Yamaguchi K, Eguchi T, et al. Mucinous cystic tumor of the pancreas: immunohistochemical assessment of "ovarian-type stroma”. Oncol Rep 2003;10:515-525.

21. O’Toole D, Palazzo L, Hammel P, et al. Macrocystic pancreatic cystadenoma: the role of EUS and cyst fluid analysis in distinguishing mucinous and serous lesions. Gastrointest Endosc 2004;59:823-829.

22. Brugge WR, Lewandrowski K, Lee-Lewandrowski E, et al. Diagnosis of pancreatic cystic neoplasms: a report of the cooperative pancreatic cyst study. Gastroenterology 2004;126:1330-1336.

23. Tanaka M, Fernández-del Castillo C, Adsay V, et al. International consensus guidelines 2012 for the management of IPMN and MCN of the pancreas. Pancreatology 2012;12:183-197.

24. Galanis C, Zamani A, Cameron JL, et al. Resected serous cystic neoplasms of the pancreas: a review of 158 patients with recommendations for treatment. J Gastrointest Surg 2007;11:820-826.

25. Tseng JF, Warshaw AL, Sahani DV, Lauwers GY, Rattner DW, Fernandez-del Castillo C. Serous cystadenoma of the pancreas: tumor growth rates and recommendations for treatment. Ann Surg 2005;242:413-419.

26. Le Borgne J, de Calan L, Partensky C. Cystadenomas and cystadenocarcinomas of the pancreas: a multiinstitutional retrospective study of 398 cases. French Surgical Association. Ann Surg 1999; 230:152-161.

27. Bassi C, Salvia R, Molinari E, Biasutti C, Falconi M, Pederzoli P. Management of 100 consecutive cases of pancreatic serous cystadenoma: wait for symptoms and see at imaging or vice versa? World J Surg 2003;27:319-323.

28. Hochwald SN, Rofsky NM, Dobryansky M, Shamamian P, Marcus SG. Magnetic resonance imaging with magnetic resonance cholangiopancreatography accurately predicts resectability of pancreatic carcinoma. J Gastrointest Surg 1999;3:506-511.

29. Kimura W, Moriya T, Hirai I, et al. Multicenter study of serous cystic neoplasm of the Japan Pancreas Society. Pancreas 2012;41: 380-387.

30. King JC, Ng TT, White SC, Cortina G, Reber HA, Hines OJ. Pancreatic serous cystadenocarcinoma: a case report and review of the literature. J Gastrointest Surg 2009;13:1864-1868.

31. Khashab MA, Shin EJ, Amateau S, et al. Tumor size and location 
correlate with behavior of pancreatic serous cystic neoplasms. Am J Gastroenterol 2011;106:1521-1526.

32. Malleo G, Bassi C, Rossini R, et al. Growth pattern of serous cystic neoplasms of the pancreas: observational study with long-term magnetic resonance surveillance and recommendations for treatment. Gut 2012;61:746-751.

33. Hwang HK, Kim H, Kang CM, Lee WJ. Serous cyst adenoma of the pancreas: appraisal of active surgical strategy before it causes problems. Surg Endosc 2012;26:1560-1565.

34. Menard A, Tomlinson G, Cleary S, Wei A, Gallinger S, Haider MA. Serous cystadenomas of the pancreas: long-term follow-up measurement of growth rate. Can Assoc Radiol J 2011;62:190196.

35. Imaoka H, Yamao K, Salem AA, et al. Pancreatic endocrine neoplasm can mimic serous cystadenoma. Int J Gastrointest Cancer 2005;35:217-220.

36. Sahara S, Kawai N, Sato M, et al. Differentiation of pancreatic serous cystadenoma from endocrine tumor and intraductal papillary mucinous neoplasm based on washout pattern on multiphase CT. J Comput Assist Tomogr 2012;36:231-236.

37. Hayashi K, Fujimitsu R, Ida M, et al. CT differentiation of solid serous cystadenoma vs endocrine tumor of the pancreas. Eur J Radiol 2012;81:e203-e208.

38. Gerke H, Silva R, Jensen CS. Hypervascular pancreatic tumor diagnosed as a serous cystadenoma by EUS-guided Trucut biopsy. Gastrointest Endosc 2006;64:273-274.

39. Hammel PR, Vilgrain V, Terris B, et al. Pancreatic involvement in von Hippel-Lindau disease. The Groupe Francophone d'Etude de la Maladie de von Hippel-Lindau. Gastroenterology 2000;119: 1087-1095.

40. Charlesworth M, Verbeke CS, Falk GA, Walsh M, Smith AM, Morris-Stiff G. Pancreatic lesions in von Hippel-Lindau disease? A systematic review and meta-synthesis of the literature. J Gastrointest Surg 2012;16:1422-1428.

41. Panarelli NC, Park KJ, Hruban RH, Klimstra DS. Microcystic serous cystadenoma of the pancreas with subtotal cystic degeneration: another neoplastic mimic of pancreatic pseudocyst. Am J Surg Pathol 2012;36:726-731.

42. Moore PS, Zamboni G, Brighenti A, et al. Molecular characterization of pancreatic serous microcystic adenomas: evidence for a tumor suppressor gene on chromosome 10q. Am J Pathol 2001; 158:317-321

43. Thirabanjasak D, Basturk O, Altinel D, Cheng JD, Adsay NV. Is serous cystadenoma of the pancreas a model of clear-cell-associated angiogenesis and tumorigenesis? Pancreatology 2009;9:182188.

44. Vassos N, Agaimy A, Klein P, Hohenberger W, Croner RS. Solidpseudopapillary neoplasm (SPN) of the pancreas: case series and literature review on an enigmatic entity. Int J Clin Exp Pathol 2013;6:1051-1059.

45. Papavramidis T, Papavramidis S. Solid pseudopapillary tumors of the pancreas: review of 718 patients reported in English literature.
J Am Coll Surg 2005;200:965-972.

46. Reddy S, Cameron JL, Scudiere J, et al. Surgical management of solid-pseudopapillary neoplasms of the pancreas (Franz or Hamoudi tumors): a large single-institutional series. J Am Coll Surg 2009;208:950-957.

47. Butte JM, Brennan MF, Gönen M, et al. Solid pseudopapillary tumors of the pancreas: clinical features, surgical outcomes, and long-term survival in 45 consecutive patients from a single center. J Gastrointest Surg 2011;15:350-357.

48. Serra S, Chetty R. Revision 2: an immunohistochemical approach and evaluation of solid pseudopapillary tumour of the pancreas. J Clin Pathol 2008;61:1153-1159.

49. El-Bahrawy MA, Rowan A, Horncastle D, et al. E-cadherin/ catenin complex status in solid pseudopapillary tumor of the pancreas. Am J Surg Pathol 2008;32:1-7.

50. Tanaka Y, Kato K, Notohara K, et al. Frequent beta-catenin mutation and cytoplasmic/nuclear accumulation in pancreatic solidpseudopapillary neoplasm. Cancer Res 2001;61:8401-8404.

51. Chetty R, Serra S. Loss of expression of E-cadherin in solid pseudopapillary tumors of the pancreas. Pancreas 2009;38:338.

52. Abraham SC, Klimstra DS, Wilentz RE, et al. Solid-pseudopapillary tumors of the pancreas are genetically distinct from pancreatic ductal adenocarcinomas and almost always harbor betacatenin mutations. Am J Pathol 2002;160:1361-1369.

53. Geers C, Moulin P, Gigot JF, et al. Solid and pseudopapillary tumor of the pancreas: review and new insights into pathogenesis. Am J Surg Pathol 2006;30:1243-1249.

54. Morales A, Ruíz Molina JM, Estéves HO, Robles-Díaz G, DíazSánchez V. Papillary-cystic neoplasm of the pancreas: a sexsteroid dependent tumor. Int J Pancreatol 1998;24:219-225.

55. Fried P, Cooper J, Balthazar E, Fazzini E, Newall J. A role for radiotherapy in the treatment of solid and papillary neoplasms of the pancreas. Cancer 1985;56:2783-2785.

56. Gaujoux S, Tang L, Klimstra D, et al. The outcome of resected cystic pancreatic endocrine neoplasms: a case-matched analysis. Surgery 2012;151:518-525.

57. Boninsegna L, Partelli S, D’Innocenzio MM, et al. Pancreatic cystic endocrine tumors: a different morphological entity associated with a less aggressive behavior. Neuroendocrinology 2010;92:246-251.

58. Bordeianou L, Vagefi PA, Sahani D, et al. Cystic pancreatic endocrine neoplasms: a distinct tumor type? J Am Coll Surg 2008;206:1154-1158.

59. Federle MP, McGrath KM. Cystic neoplasms of the pancreas. Gastroenterol Clin North Am 2007;36:365-376.

60. Singhi AD, Chu LC, Tatsas AD, et al. Cystic pancreatic neuroendocrine tumors: a clinicopathologic study. Am J Surg Pathol 2012;36:1666-1673.

61. Ho HC, Eloubeidi MA, Siddiqui UD, et al. Endosonographic and cyst fluid characteristics of cystic pancreatic neuroendocrine tumours: a multicentre case series. Dig Liver Dis 2013;45:750-753.

62. Ligneau B, Lombard-Bohas C, Partensky C, et al. Cystic endocrine 
tumors of the pancreas: clinical, radiologic, and histopathologic features in 13 cases. Am J Surg Pathol 2001;25:752-760.

63. Kongkam P, Al-Haddad M, Attasaranya S, et al. EUS and clinical characteristics of cystic pancreatic neuroendocrine tumors. Endoscopy 2008;40:602-605.

64. Goh BK, Ooi LL, Tan YM, et al. Clinico-pathological features of cystic pancreatic endocrine neoplasms and a comparison with their solid counterparts. Eur J Surg Oncol 2006;32:553-556.

65. Yoon WJ, Daglilar ES, Pitman MB, Brugge WR. Cystic pancreatic neuroendocrine tumors: endoscopic ultrasound and fine-needle aspiration characteristics. Endoscopy 2013;45:189-194.

66. Davtyan H, Nieberg R, Reber HA. Pancreatic cystic endocrine neoplasms. Pancreas 1990;5:230-233.

67. Kamisawa T, Fukayama M, Koike M, Tabata I, Okamoto A. A case of malignant cystic endocrine tumor of the pancreas. Am J Gastroenterol 1987;82:86-89.

68. Fernández-del Castillo C, Warshaw AL. Cystic tumors of the pancreas. Surg Clin North Am 1995;75:1001-1016.

69. Lee LC, Grant CS, Salomao DR, et al. Small, nonfunctioning, asymptomatic pancreatic neuroendocrine tumors (PNETs): role for nonoperative management. Surgery 2012;152:965-974.

70. Fernández-del Castillo C, Adsay NV. Intraductal papillary mucinous neoplasms of the pancreas. Gastroenterology 2010;139:708713.e2.

71. Adsay NV, Conlon KC, Zee SY, Brennan MF, Klimstra DS. Intraductal papillary-mucinous neoplasms of the pancreas: an analysis of in situ and invasive carcinomas in 28 patients. Cancer 2002;94:62-77.

72. Fukushima N, Mukai K, Sakamoto M, et al. Invasive carcinoma derived from intraductal papillary-mucinous carcinoma of the pancreas: clinicopathologic and immunohistochemical study of eight cases. Virchows Arch 2001;439:6-13.

73. Klöppel G. Clinicopathologic view of intraductal papillary-mucinous tumor of the pancreas. Hepatogastroenterology 1998;45: 1981-1985.

74. Cuillerier E, Cellier C, Palazzo L, et al. Outcome after surgical resection of intraductal papillary and mucinous tumors of the pancreas. Am J Gastroenterol 2000;95:441-445.

75. Crippa S, Fernández-Del Castillo C, Salvia R, et al. Mucinproducing neoplasms of the pancreas: an analysis of distinguishing clinical and epidemiologic characteristics. Clin Gastroenterol Hepatol 2010;8:213-219.

76. Furukawa T, Hatori T, Fujita I, et al. Prognostic relevance of morphological types of intraductal papillary mucinous neoplasms of the pancreas. Gut 2011;60:509-516.

77. Farrell JJ, Fernández-del Castillo C. Pancreatic cystic neoplasms: management and unanswered questions. Gastroenterology 2013; 144:1303-1315.

78. Sohn TA, Yeo CJ, Cameron JL, et al. Intraductal papillary mucinous neoplasms of the pancreas: an updated experience. Ann Surg 2004;239:788-797.

79. Maguchi H, Tanno S, Mizuno N, et al. Natural history of branch duct intraductal papillary mucinous neoplasms of the pancreas: a multicenter study in Japan. Pancreas 2011;40:364-370.

80. Lévy P, Jouannaud V, O’Toole D, et al. Natural history of intraductal papillary mucinous tumors of the pancreas: actuarial risk of malignancy. Clin Gastroenterol Hepatol 2006;4:460-468.

81. Wasif N, Bentrem DJ, Farrell JJ, et al. Invasive intraductal papillary mucinous neoplasm versus sporadic pancreatic adenocarcinoma: a stage-matched comparison of outcomes. Cancer 2010;116:3369-3377.

82. Adsay NV, Merati K, Basturk 0, et al. Pathologically and biologically distinct types of epithelium in intraductal papillary mucinous neoplasms: delineation of an "intestinal" pathway of carcinogenesis in the pancreas. Am J Surg Pathol 2004;28:839-848.

83. Poultsides GA, Reddy S, Cameron JL, et al. Histopathologic basis for the favorable survival after resection of intraductal papillary mucinous neoplasm-associated invasive adenocarcinoma of the pancreas. Ann Surg 2010;251:470-476.

84. Mino-Kenudson M, Fernández-del Castillo C, Baba Y, et al. Prognosis of invasive intraductal papillary mucinous neoplasm depends on histological and precursor epithelial subtypes. Gut 2011;60:1712-1720.

85. Lüttges J, Zamboni G, Longnecker D, Klöppel G. The immunohistochemical mucin expression pattern distinguishes different types of intraductal papillary mucinous neoplasms of the pancreas and determines their relationship to mucinous noncystic carcinoma and ductal adenocarcinoma. Am J Surg Pathol 2001;25:942-948.

86. Furukawa T, Klöppel G, Volkan Adsay N, et al. Classification of types of intraductal papillary-mucinous neoplasm of the pancreas: a consensus study. Virchows Arch 2005;447:794-799.

87. Sadakari Y, Ohuchida K, Nakata K, et al. Invasive carcinoma derived from the nonintestinal type intraductal papillary mucinous neoplasm of the pancreas has a poorer prognosis than that derived from the intestinal type. Surgery 2010;147:812-817.

88. Strobel 0, Rosow DE, Rakhlin EY, et al. Pancreatic duct glands are distinct ductal compartments that react to chronic injury and mediate Shh-induced metaplasia. Gastroenterology 2010;138:11661177.

89. Canto MI, Hruban RH, Fishman EK, et al. Frequent detection of pancreatic lesions in asymptomatic high-risk individuals. Gastroenterology 2012;142:796-804.

90. Hruban RH, Adsay NV, Albores-Saavedra J, et al. Pancreatic intraepithelial neoplasia: a new nomenclature and classification system for pancreatic duct lesions. Am J Surg Pathol 2001;25:579-586.

91. Basturk 0, Khayyata S, Klimstra DS, et al. Preferential expression of MUC6 in oncocytic and pancreatobiliary types of intraductal papillary neoplasms highlights a pyloropancreatic pathway, distinct from the intestinal pathway, in pancreatic carcinogenesis. Am J Surg Pathol 2010;34:364-370.

92. Patel SA, Adams R, Goldstein M, Moskaluk CA. Genetic analysis of invasive carcinoma arising in intraductal oncocytic papillary neoplasm of the pancreas. Am J Surg Pathol 2002;26:1071-1077. 
93. Tajiri T, Tate G, Kunimura T, et al. Histologic and immunohistochemical comparison of intraductal tubular carcinoma, intraductal papillary-mucinous carcinoma, and ductal adenocarcinoma of the pancreas. Pancreas 2004;29:116-122.

94. Kanda M, Sadakari Y, Borges M, et al. Mutant TP53 in duodenal samples of pancreatic juice from patients with pancreatic cancer or high-grade dysplasia. Clin Gastroenterol Hepatol 2013;11:719730.e5.

95. Xiao HD, Yamaguchi H, Dias-Santagata D, et al. Molecular characteristics and biological behaviours of the oncocytic and pancreatobiliary subtypes of intraductal papillary mucinous neoplasms. J Pathol 2011;224:508-516.

96. Wu J, Matthaei H, Maitra A, et al. Recurrent GNAS mutations define an unexpected pathway for pancreatic cyst development. Sci Transl Med 2011;3:92ra66.

97. Dal Molin M, Matthaei H, Wu J, et al. Clinicopathological correlates of activating GNAS mutations in intraductal papillary mucinous neoplasm (IPMN) of the pancreas. Ann Surg Oncol 2013;20: 3802-3808.

98. Matthaei H, Norris AL, Tsiatis AC, et al. Clinicopathological characteristics and molecular analyses of multifocal intraductal papillary mucinous neoplasms of the pancreas. Ann Surg 2012;255:326-333.

99. Hong SM, Omura N, Vincent A, et al. Genome-wide CpG island profiling of intraductal papillary mucinous neoplasms of the pancreas. Clin Cancer Res 2012;18:700-712.

100. Hong SM, Vincent A, Kanda M, et al. Genome-wide somatic copy number alterations in low-grade PanINs and IPMNs from individuals with a family history of pancreatic cancer. Clin Cancer Res 2012;18:4303-4312.

101. Habbe N, Koorstra JB, Mendell JT, et al. MicroRNA miR-155 is a biomarker of early pancreatic neoplasia. Cancer Biol Ther 2009;8: 340-346.

102. Farrell JJ, Toste $\mathrm{P}, \mathrm{Wu} \mathrm{N}$, et al. Endoscopically acquired pancreatic cyst fluid microRNA 21 and 221 are associated with invasive cancer. Am J Gastroenterol 2013;108:1352-1359.

103. Matthaei H, Wylie D, Lloyd MB, et al. miRNA biomarkers in cyst fluid augment the diagnosis and management of pancreatic cysts. Clin Cancer Res 2012;18:4713-4724.

104. Rebours V, Couvelard A, Peyroux JL, et al. Familial intraductal papillary mucinous neoplasms of the pancreas. Dig Liver Dis 2012;44:442-446.

105. Ingkakul T, Warshaw AL, Fernández-Del Castillo C. Epidemiology of intraductal papillary mucinous neoplasms of the pancreas: sex differences between 3 geographic regions. Pancreas 2011;40:779780.

106. Hara H, Suda K, Oyama T. Cytologic study of noninvasive intraductal papillary-mucinous carcinoma of the pancreas. Acta Cytol 2002;46:519-526

107. Kurihara K, Nagai H, Kasahara K, Kanazawa K, Kanai N. Biliopancreatic fistula associated with intraductal papillary-mucinous pancreatic cancer: institutional experience and review of the lit- erature. Hepatogastroenterology 2000;47:1164-1167.

108. Yamaguchi K, Kanemitsu S, Hatori T, et al. Pancreatic ductal adenocarcinoma derived from IPMN and pancreatic ductal adenocarcinoma concomitant with IPMN. Pancreas 2011;40:571-580.

109. Ideno N, Ohtsuka T, Kono H, et al. Intraductal papillary mucinous neoplasms of the pancreas with distinct pancreatic ductal adenocarcinomas are frequently of gastric subtype. Ann Surg 2013;258:141-151.

110. Correa-Gallego C, Ferrone CR, Thayer SP, et al. Incidental pancreatic cysts: do we really know what we are watching? Pancreatology 2010;10:144-150.

111. Tanaka M, Chari S, Adsay V, et al. International consensus guidelines for management of intraductal papillary mucinous neoplasms and mucinous cystic neoplasms of the pancreas. Pancreatology 2006;6:17-32.

112. Fritz S, Schirren M, Klauss M, et al. Clinicopathologic characteristics of patients with resected multifocal intraductal papillary mucinous neoplasm of the pancreas. Surgery 2012;152(3 Suppl 1):S74-S80.

113. Wong J, Weber J, Centeno BA, et al. High-grade dysplasia and adenocarcinoma are frequent in side-branch intraductal papillary mucinous neoplasm measuring less than $3 \mathrm{~cm}$ on endoscopic ultrasound. J Gastrointest Surg 2013;17:78-84.

114. Tang RS, Weinberg B, Dawson DW, et al. Evaluation of the guidelines for management of pancreatic branch-duct intraductal papillary mucinous neoplasm. Clin Gastroenterol Hepatol 2008;6:815-819.

115. Rodriguez JR, Salvia R, Crippa S, et al. Branch-duct intraductal papillary mucinous neoplasms: observations in 145 patients who underwent resection. Gastroenterology 2007;133:72-79.

116. Pelaez-Luna M, Chari ST, Smyrk TC, et al. Do consensus indications for resection in branch duct intraductal papillary mucinous neoplasm predict malignancy? A study of 147 patients. Am J Gastroenterol 2007;102:1759-1764.

117. Weinberg BM, Spiegel BM, Tomlinson JS, Farrell JJ. Asymptomatic pancreatic cystic neoplasms: maximizing survival and quality of life using Markov-based clinical nomograms. Gastroenterology 2010;138:531-540.

118. Tanno S, Nakano Y, Nishikawa T, et al. Natural history of branch duct intraductal papillary-mucinous neoplasms of the pancreas without mural nodules: long-term follow-up results. Gut 2008;57:339-343.

119. Mori Y, Ohtsuka T, Kono H, et al. Management strategy for multifocal branch duct intraductal papillary mucinous neoplasms of the pancreas. Pancreas 2012;41:1008-1012.

120. Berland LL, Silverman SG, Gore RM, et al. Managing incidental findings on abdominal CT: white paper of the ACR incidental findings committee. J Am Coll Radiol 2010;7:754-773.

121. Nehra D, Oyarvide VM, Mino-Kenudson M, et al. Intraductal papillary mucinous neoplasms: does a family history of pancreatic cancer matter? Pancreatology 2012;12:358-363.

122. Kang MJ, Jang JY, Kim SJ, et al. Cyst growth rate predicts ma- 
lignancy in patients with branch duct intraductal papillary mucinous neoplasms. Clin Gastroenterol Hepatol 2011;9:87-93.

123. Miller JR, Meyer JE, Waters JA, et al. Outcome of the pancreatic remnant following segmental pancreatectomy for non-invasive intraductal papillary mucinous neoplasm. HPB (Oxford) 2011;13: 759-766.

124. Khannoussi W, Vullierme MP, Rebours V, et al. The long term risk of malignancy in patients with branch duct intraductal papillary mucinous neoplasms of the pancreas. Pancreatology 2012;12:198-202.

125. Osiro S, Rodriguez JR, Tiwari KJ, et al. Is preoperative diagnosis possible? A clinical and radiological review of lymphoepithelial cysts of the pancreas. JOP 2013;14:15-20.

126. Nasr J, Sanders M, Fasanella K, Khalid A, McGrath K. Lymphoepithelial cysts of the pancreas: an EUS case series. Gastrointest Endosc 2008;68:170-173.

127. Coe A, Conway J, Evans J, Goebel M, Mishra G. The yield of EUS-FNA in undiagnosed upper abdominal adenopathy is very high. J Clin Ultrasound 2013;41:210-213.

128. Jathal A, Arsenescu R, Crowe G, Movva R, Shamoun DK. Diagnosis of pancreatic cystic lymphangioma with EUS-guided FNA: report of a case. Gastrointest Endosc 2005;61:920-922.

129. Bhatia V, Rastogi A, Saluja SS, et al. Cystic pancreatic lymphangioma: the first report of a preoperative pathological diagnosis by endoscopic ultrasound-guided cyst aspiration. JOP 2011;12:473476.

130. Paik KY, Choi SH, Heo JS, Choi DW. Solid tumors of the pancreas can put on a mask through cystic change. World J Surg Oncol 2011;9:79.

131. Sahani DV, Lin DJ, Venkatesan AM, et al. Multidisciplinary approach to diagnosis and management of intraductal papillary mucinous neoplasms of the pancreas. Clin Gastroenterol Hepatol 2009;7:259-269.

132. Chaudhari VV, Raman SS, Vuong NL, et al. Pancreatic cystic lesions: discrimination accuracy based on clinical data and high resolution CT features. J Comput Assist Tomogr 2007;31:860867.

133. Kim JH, Eun HW, Park HJ, Hong SS, Kim YJ. Diagnostic performance of MRI and EUS in the differentiation of benign from malignant pancreatic cyst and cyst communication with the main duct. Eur J Radiol 2012;81:2927-2935.

134. Lee LS, Saltzman JR, Bounds BC, Poneros JM, Brugge WR, Thompson CC. EUS-guided fine needle aspiration of pancreatic cysts: a retrospective analysis of complications and their predictors. Clin Gastroenterol Hepatol 2005;3:231-236.

135. Pitman MB, Genevay M, Yaeger K, et al. High-grade atypical epithelial cells in pancreatic mucinous cysts are a more accurate predictor of malignancy than "positive" cytology. Cancer Cytopathol 2010;118:434-440

136. van der Waaij LA, van Dullemen HM, Porte RJ. Cyst fluid analysis in the differential diagnosis of pancreatic cystic lesions: a pooled analysis. Gastrointest Endosc 2005;62:383-389.
137. Othman MO, Patel M, Dabizzi E, et al. Carcino embryonic antigen and long-term follow-up of mucinous pancreatic cysts including intraductal papillary mucinous neoplasm. Dig Liver Dis 2012; 44:844-848.

138. Al-Haddad M, DeWitt J, Sherman S, et al. Performance characteristics of molecular (DNA) analysis for the diagnosis of mucinous pancreatic cysts. Gastrointest Endosc 2014;79:79-87.

139. Siddiqui AA, Kowalski TE, Kedika R, et al. EUS-guided pancreatic fluid aspiration for DNA analysis of KRAS and GNAS mutations for the evaluation of pancreatic cystic neoplasia: a pilot study. Gastrointest Endosc 2013;77:669-670.

140. Rockacy MJ, Zahid M, McGrath KM, Fasanella KE, Khalid A. Association between KRAS mutation, detected in pancreatic cyst fluid, and long-term outcomes of patients. Clin Gastroenterol Hepatol 2013;11:425-429.

141. Mertz H. K-ras mutations correlate with atypical cytology and elevated CEA levels in pancreatic cystic neoplasms. Dig Dis Sci 2011;56:2197-2201.

142. Toll AD, Kowalski T, Loren D, Bibbo M. The added value of molecular testing in small pancreatic cysts. JOP 2010;11:582-586.

143. Shen J, Brugge WR, Dimaio CJ, Pitman MB. Molecular analysis of pancreatic cyst fluid: a comparative analysis with current practice of diagnosis. Cancer 2009;117:217-227.

144. Sreenarasimhaiah J, Lara LF, Jazrawi SF, Barnett CC, Tang SJ. A comparative analysis of pancreas cyst fluid CEA and histology with DNA mutational analysis in the detection of mucin producing or malignant cysts. JOP 2009;10:163-168.

145. Sawhney MS, Devarajan S, O'Farrel P, et al. Comparison of carcinoembryonic antigen and molecular analysis in pancreatic cyst fluid. Gastrointest Endosc 2009;69:1106-1110.

146. Khalid A, Zahid M, Finkelstein SD, et al. Pancreatic cyst fluid DNA analysis in evaluating pancreatic cysts: a report of the PANDA study. Gastrointest Endosc 2009;69:1095-1102.

147. Gan SI, Thompson CC, Lauwers GY, Bounds BC, Brugge WR. Ethanol lavage of pancreatic cystic lesions: initial pilot study. Gastrointest Endosc 2005;61:746-752.

148. Oh HC, Seo DW, Song TJ, et al. Endoscopic ultrasonographyguided ethanol lavage with paclitaxel injection treats patients with pancreatic cysts. Gastroenterology 2011;140:172-179.

149. Oh HC, Brugge WR. EUS-guided pancreatic cyst ablation: a critical review (with video). Gastrointest Endosc 2013;77:526-533.

150. Oh HC, Seo DW. Ablate under EUS-guidance when properly indicated. Gastroenterology 2011;141:e20-e21.

151. Oh HC, Seo DW, Lee TY, et al. New treatment for cystic tumors of the pancreas: EUS-guided ethanol lavage with paclitaxel injection. Gastrointest Endosc 2008;67:636-642.

152. Oh HC, Seo DW, Song TJ, et al. Endoscopic ultrasonographyguided ethanol lavage with paclitaxel injection treats patients with pancreatic cysts. Gastroenterology 2011;140:172-179.

153. DeWitt J, McGreevy K, Schmidt CM, Brugge WR. EUS-guided ethanol versus saline solution lavage for pancreatic cysts: a randomized, double-blind study. Gastrointest Endosc 2009;70:710- 
723.

154. Imaoka H, Yamao K, Salem AA, et al. Pancreatic endocrine neoplasm can mimic serous cystadenoma. Int J Gastrointest Cancer 2005;35:217-220.

155. Gerke H, Silva R, Jensen CS. Hypervascular pancreatic tumor diagnosed as a serous cystadenoma by EUS-guided Trucut biopsy. Gastrointest Endosc 2006;64:273-274.

156. Salvia R, Bassi C, Falconi M, et al. Intraductal papillary mucinous tumors of the pancreas. Surgical treatment: at what point should we stop? JOP 2005;6(1 Suppl):112-117.

157. Gaujoux S, Brennan MF, Gonen M, et al. Cystic lesions of the pancreas: changes in the presentation and management of 1,424 patients at a single institution over a 15-year time period. J Am Coll Surg 2011;212:590-600.

158. Sahora K, Mino-Kenudson M, Brugge W, et al. Branch duct intraductal papillary mucinous neoplasms: does cyst size change the tip of the scale? A critical analysis of the revised international consensus guidelines in a large single-institutional series. Ann Surg 2013;258:466-475.

159. Lee LS, Clancy T, Kadiyala V, Suleiman S, Conwell DL. Interdisciplinary management of cystic neoplasms of the pancreas. Gastroenterol Res Pract 2012;2012:513163.

160. Lennon AM, Manos LL, Hruban RH, et al. Role of a multidis- ciplinary clinic in the management of patients with pancreatic cysts: a single-center cohort study. Ann Surg Oncol 2014;21: 3668-3674.

161. Nair RM, Barthel JS, Centeno BA, Choi J, Klapman JB, Malafa MP. Interdisciplinary management of an intraductal papillary mucinous neoplasm of the pancreas. Cancer Control 2008; 15:322-333.

162. Jabbar KS, Verbeke C, Hyltander AG, Sjövall H, Hansson GC, Sadik R. Proteomic mucin profiling for the identification of cystic precursors of pancreatic cancer. J Natl Cancer Inst 2014;106: djt439.

163. Maker AV, Katabi N, Gonen M, et al. Pancreatic cyst fluid and serum mucin levels predict dysplasia in intraductal papillary mucinous neoplasms of the pancreas. Ann Surg Oncol 2011;18:199206.

164. Carrara S, Cangi MG, Arcidiacono PG, et al. Mucin expression pattern in pancreatic diseases: findings from EUS-guided fineneedle aspiration biopsies. Am J Gastroenterol 2011;106:13591363.

165. Ryu JK, Matthaei H, Dal Molin M, et al. Elevated microRNA miR21 levels in pancreatic cyst fluid are predictive of mucinous precursor lesions of ductal adenocarcinoma. Pancreatology 2011;11: 343-350. 